\title{
Article \\ The Role of the Discount Policy of Prepayment on Environmentally Friendly Inventory Management
}

\author{
Shirin Sultana ${ }^{1}\left(\mathbb{D}\right.$, Abu Hashan Md Mashud ${ }^{2} \mathbb{D}$, Yosef Daryanto ${ }^{3} \mathbb{D}$, Sujan Miah ${ }^{4}$, , Adel Alrasheedi ${ }^{5}$ \\ and Ibrahim M. Hezam $5, *$ (D)
}

1 Department of General Educational Development, Daffodil International University, Dhaka 1341, Bangladesh; shirin.ged@daffodilvarsity.edu.bd

2 School of Engineering and IT, University of New South Wales (UNSW), Campbell, Canberra, ACT 2612, Australia; a.mashud@adfa.edu.au

3 Department of Industrial Engineering, Universitas Atma Jaya Yogyakarta, Yogyakarta 55281, Indonesia; yosef.daryanto@uajy.ac.id

4 Department of Mathematics, Hajee Mohammad Danesh Science and Technology University, Dinajpur 5200, Bangladesh; sujan1608217@std.hstu.ac.bd

5 Department of Statistics \& Operations Research, College of Sciences, King Saud University, Riyadh 11451, Saudi Arabia; aalrasheedi@ksu.edu.sa

* Correspondence: ialmishnanah@ksu.edu.sa

Citation: Sultana, S.; Mashud, A.H.M.; Daryanto, Y.; Miah, S.; Alrasheedi, A.; Hezam, I.M. The Role of the Discount Policy of Prepayment on Environmentally Friendly Inventory Management. Fractal Fract. 2022, 6, 26. https://doi.org/ $10.3390 /$ fractalfract 6010026

Academic Editor: Savin Treanţă

Received: 25 November 2021

Accepted: 30 December 2021

Published: 2 January 2022

Publisher's Note: MDPI stays neutra with regard to jurisdictional claims in published maps and institutional affiliations.

Copyright: (C) 2022 by the authors. Licensee MDPI, Basel, Switzerland. This article is an open access article distributed under the terms and conditions of the Creative Commons Attribution (CC BY) license (https:// creativecommons.org/licenses/by/ $4.0 /)$.
Abstract: Nowadays, more and more consumers consider environmentally friendly products in their purchasing decisions. Companies need to adapt to these changes while paying attention to standard business systems such as payment terms. The purpose of this study is to optimize the entire profit function of a retailer and to find the optimal selling price and replenishment cycle when the demand rate depends on the price and carbon emission reduction level. This study investigates an economic order quantity model that has a demand function with a positive impact of carbon emission reduction besides the selling price. In this model, the supplier requests payment in advance on the purchased cost while offering a discount according to the payment in the advanced decision. Three different types of payment-in-advance cases are applied: (1) payment in advance with equal numbers of instalments, (2) payment in advance with a single instalment, and (3) the absence of payment in advance. Numerical examples and sensitivity analysis illustrate the proposed model. Here, the total profit increases for all three cases with higher values of carbon emission reduction level. Further, the study finds that the profit becomes maximum for case 2, whereas the selling price and cycle length become minimum. This study considers the sustainable inventory model with payment-in-advance settings when the demand rate depends on the price and carbon emission reduction level. From the literature review, no researcher has undergone this kind of study in the authors' knowledge.

Keywords: low carbon inventory; discount; payment in advance; price-sensitive demand; emission reduction

\section{Introduction}

Customer preferences have always been a concern in industries in terms of their effect on business growth. Customer preferences are affected by many factors and are reflected in the customers' willingness to buy. The level of consumer demand is usually sensitive to product prices. However, in today's setting, more and more consumers consider the environmental performance of the producer and the green level of product in their purchasing decisions [1-3]. This trend is expanding globally along with the increasing consumer awareness of the importance of environmental conservation in the midst of climate change issues. Hence, many producers and retailers innovate green products and promote green operations to attract these customers [4,5]. Moreover, regulations become another driver for this eco-innovation. Companies try to reduce carbon emissions from 
production, logistics, and transportation activities and apply green technology to meet new regulations and pressure from these customers.

The inventory decisions on supply chain operations already incorporate environmental parameters with certain intentions such as reducing carbon emission levels. Previous supply chain studies also consider customers' awareness of low carbon emissions [6-8], the green quality of the product $[9,10]$, and the amount of carbon emissions [11], which affect the demand level. Customer awareness and green quality level have positive impacts on the demand function of green products, while the amount of carbon emissions has the opposite effect. Green marketing becomes a powerful strategy for businesses through various green advertising, branding, and eco-labeling. This strategy has been adopted to promote many international and local brands and products in both developed and developing countries [12-16]. Xia et al. [7] incorporated the positive effect of emission reduction and the promotion of this environmental benefit into the demand function. Recently, Dong et al. [17] considered the manufacturer's reduction in carbon emission levels, which shows the company's initiative for greener operations. The positive effect of carbon emission reduction on customer demand was combined with the negative effect of the selling price. The study also examined the payment issue by analyzing the effect of trade credit and bank loans. Based on Dong et al. [17], we study a sustainable inventory model considering a prepayment mechanism, another common payment term in business, in order to consider a real situation.

The payment term in the transaction between a supplier and a buyer is an important issue in supply chain collaboration. The term should be agreed upon by both parties so that it is clear and beneficial for all. The classic economic order quantity (EOQ) model assumes a payment immediately after product delivery. However, in many cases, payment in advance is applied, in which the buyer should pay the purchase cost before the product delivery. The buyer may have to pay all the purchase cost in advance [18-20] or pay only a percentage of it $[19,21]$. Further, the prepayment can be done in several time intervals [22,23]. While the payment in advance will give the supplier an advantage by mitigating the risk of cancellation, the supplier can offer some discounts to the buyer so that they benefit as well. Our study considers discount offers similar to Mashud et al. [23].

The increase in customers' awareness of green issues, together with the trend in producers' concern on carbon emission reduction and the common practices of payment in advance, has motivated this study to contribute to the development of a sustainable inventory model. This paper presents a profit maximization study of a retailer inventory system to respond to customers' increasing low carbon preferences. When customer demand depends on the selling price and the retailer must pay the purchase cost in advance, the proposed model suggests the optimum replenishment time and selling price. The study aims at providing managerial insights by answering the following questions:

a. How do payment-in-advance models affect pricing and replenishment decisions as well as the total profit when customer demand is sensitive to the selling price and environmental performance of the producer?

b. Will discount policy impact retailers' choice of payment in advance settings and total profit?

c. How do the customer preference for carbon emission reduction levels and various emission costs impact the retailer's total profit?

In this paper, we first study the retailer's optimal selling price and replenishment cycle when payment in advance is fulfilled with some equal numbers of instalments and a discount is offered by the supplier. Then, we address the same issue when the purchase cost is completed in a single payment, and in return, the customer will get a different discount rate. Next, we study the situation in which no payment in advance is considered, hence no discount is offered. 


\section{Literature Review}

Traditional inventory management focuses on the economic benefit from a business point of view. For example, the classic inventory model works under some basic assumptions such as infinite replenishment and planning horizon that aim at optimizing financial profit. In recent years, considerable attention has shifted to economic and environmental aspects of the emergence of the sustainable inventory model terminology. The focus has broadened to include minimizing environmental impacts through carbon emission reductions, energy efficiency, and the adoption of green technologies [24,25]. Most sustainable inventory models seek to reduce supply chain emission levels by considering emissions from production, transportation, and inventory storage activities. Carbon tax systems are widely used to include the cost of carbon emissions in the objective function [26-31]. Other carbon regulations such as carbon cap-and-trade and strict carbon limits are also used, depending on the regulations imposed by the government [32,33]. Datta [34] developed an inventory model with investment in emission reduction technology focusing on emissions from production activities. The study considered carbon emission reduction under a carbon tax policy and optimization of the investment amount. Under a similar carbon tax policy, Mashud et al. [35] considered emission reduction from transportation activities. Simultaneous investments for emission reduction and deterioration rate were studied by Mishra et al. [36]. Lou et al. [37] optimized the green technology investment considering a subsidy from the government. Optimum investment level was considered important because customer demand was assumed to be sensitive to emission reduction level. The study recommended an active role from the government such as providing technology investment subsidies and controlling the emission trading price.

In addition to government regulations, efforts to reduce carbon emission levels are also driven by the increasing number of consumers who consider environmental aspects in their purchasing decisions [9]. Hence, the environmental performance of the product was added to the demand function. Pang et al. [6] and Gao et al. [38] considered the customers' environmental awareness and set a linear demand function in addition to the effect of selling price on demand. Hovelaque and Bironneau [11] set a demand function that depends on price and the amount of carbon emissions. They found two order quantities, one that will maximize the total profit and another one that will minimize the emission level. Lou et al. [37] also set a demand function with a linear effect of price and emission reduction. The percentage of emission reduction per unit product was optimized together with the selling price. Xia et al. [7] incorporated a promotion strategy to support the emission reduction program to gain customer attention. Zhang et al. [3] analyzed a manufacturer's decision to introduce a new green product to customers with high environmental awareness. The study found a conflict if the manufacturer also sells an ordinary product because the products will compete with each other. Recently, Dong et al. [17] considered the positive effect of carbon emission reduction and the negative effect of the selling price on the customer demand rate. For a single-supplier, single-buyer supply chain model, they also studied the effect of financial facilities such as trade credit and bank loans on the manufacturer's decision regarding the level of emission reduction. Using a similar demand function, we study an economic order quantity (EOQ) model of a retailer when payment in advance is requested by the supplier. The retailer's optimal selling price and replenishment cycle are the decision variables.

The inventory model with payment in advance is another research stream in this paper. The practices of payment in advance may be introduced by a powerful supplier to prevent order cancellation, especially for customized and expensive products [19]. The payment may help the supplier to finish the product. Maiti et al. [21] are among the first researchers who incorporated payment in advance into an inventory model. The proposed model says that the buyer gets some price discount based on the amount of the payment in advance. Further, due to the payment in advance, the retailer may need cash aid from any financial institution, which means an additional cost of interest. The buyer may have to pay all the purchase costs in advance or pay only a percentage of it $[18,19,39,40]$. 
During the payment-in-advance period, multiple instalments may be applied to reduce the retailer burden $[22,23]$. Hence, our study examines the effect of three different payment-inadvance settings-(1) payment in advance with equal numbers of instalments, (2) payment in advance with single instalment, and (3) the absence of payment in advance-on the optimum price and replenishment cycle that optimizes the profit.

\section{Mathematical Model Formulation for Inventory Model}

The proposed mathematical model is based on the following assumptions:

a. Inventory of a single product is considered with a limitless planning horizon.

b. The replenishment rate is boundless.

c. The lead time is constant and the shortages are overlooked.

d. The retailer has to make a payment in advance to the supplier [23].

e. The supplier offers a discount on the purchase cost of the products according to the number of instalment decisions [23].

f. The demand function $D_{L}=\psi-\gamma p+\eta R_{C}$ depends on price and carbon emission reduction level $[17,41,42]$. Here,

$\psi$ is the market potential

$\gamma$ is the price sensitivity coefficient $(\gamma>0)$

$p$ is the unit selling price

$\eta$ is the low carbon preference coefficient $(\eta>0)$

$R_{C}$ is the manufacturer's carbon emission reduction level

In addition, the following nomenclatures (Table 1) are used.

Table 1. Notation description.

\begin{tabular}{|c|c|c|}
\hline Notations & Units & Description \\
\hline$D_{L}$ & units & Demand function \\
\hline$F_{C}$ & $\$ /$ trip & Fixed cost of transportation \\
\hline$N_{t}$ & unit & Number of trips \\
\hline$c_{e}$ & $\$ / \mathrm{km}$ & Carbon emission cost per unit distance \\
\hline$c_{k}$ & \$/unit/km & Carbon emission cost per unit item per unit distance \\
\hline$c_{p}$ & liter/ton & Fuel consumption per ton of payload \\
\hline$f_{e}$ & liter & Empty vehicle fuel consumption \\
\hline$\hbar$ & \$/unit & Holding cost per unit \\
\hline$\ell$ & $\mathrm{km}$ & One way distance \\
\hline$n$ & unit & Number of instalments \\
\hline$w_{p}$ & $\mathrm{~kg}$ & Product weight \\
\hline$\alpha$ & \$/liter & Price of fuel \\
\hline$x$ & $\$$ & Carbon emission reduction investment \\
\hline$\delta$ & constant & Payment in advance portion of purchase cost \\
\hline$\zeta$ & \$/cycle & Ordering cost per cycle \\
\hline$\kappa$ & months & Lead time \\
\hline$\phi$ & constant & $\begin{array}{l}\text { Interest rate due to instalment based payment in } \\
\text { advance }\end{array}$ \\
\hline$\phi_{L}$ & constant & Interest rate on loan amount \\
\hline$\Omega$ & units & Order quantity \\
\hline$\omega$ & \$/unit & Purchase cost per unit \\
\hline \multicolumn{3}{|r|}{ Decision Variables } \\
\hline$p$ & \$/unit & Selling price \\
\hline$T_{C}$ & months & Replenishment time. \\
\hline
\end{tabular}

An inventory model is developed under consideration of the above assumptions. The model is divided into three cases considering the payment-in-advance cost. In Case I, payment in advance is fulfilled with some equal numbers of instalments, and a discount is offered for the retailer as a benefit according to the number of instalments. Case II considers that the payment is completed with a single instalment and, in return, the retailer will get 
a different discount from the supplier. Finally, in Case III, no payment-in-advance cost is considered, and hence no discount is offered to the retailer.

\subsection{Case I: With Advanced Payment and a Discount for Instalment Based Payment}

A retailer runs its business with an initial stock of $\Omega$ units. Depending on the demand function, the stock decreases and becomes zero at time $t=T_{C}$. Thus, one cycle ends, and the process repeats so that the business continues. To get this stock, the retailer pays a percentage of the purchase cost $(\delta)$ in $n$ equal number of instalments before the products are delivered. The amount of each prepayment is $\frac{\delta \omega \Omega}{n}$. At the moment of delivery, the retailer needs to pay for the remaining $(1-\delta) \Omega$ quantity. Figure 1 outlines the above facts and the pattern of the level of inventory.

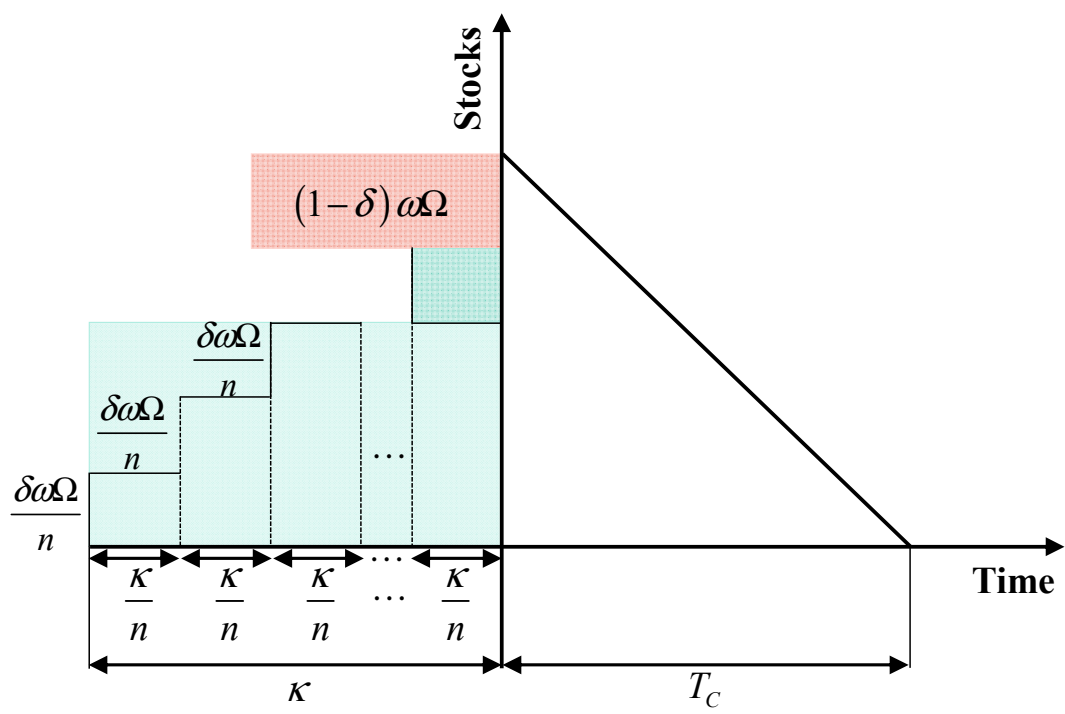

Figure 1. Graphical presentation of the inventory system for Case I.

The inventory system is described by the following differential equation considering the demand $D_{L}=\psi-\gamma p+\eta R_{C}$.

$$
\frac{d I_{S}(t)}{d t}=-D_{L}, 0 \leq t \leq T_{C}
$$

With the help of boundary conditions $I_{S}(0)=\Omega$ and $I_{S}\left(T_{C}\right)=0$, by solving Equation (1) we get,

$$
I_{S}(t)=D_{L}\left(T_{C}-t\right)
$$

and

$$
\Omega=D_{L} T_{C}
$$

\subsubsection{Total Cost per Unit Time}

(a) Ordering cost per cycle:

$$
O C=\zeta
$$

(b) The inventory holding cost per cycle:

$$
H C=\hbar \int_{0}^{T_{C}} I_{S}(t) d t=\frac{1}{2} \hbar D_{L} T_{C}^{2}
$$

(c) The purchase cost per cycle:

$$
P C=\Omega \omega
$$


(d) Transportation cost per cycle:

Three major costs are considered to estimate the transportation cost: fixed cost $\left(F_{C}\right)$, variable cost, and carbon emission cost. However, the variable cost and the carbon emission cost are different for an empty vehicle (truck) and a loaded vehicle. The total travel distance is $2 \ell$ as the vehicle has to travel a distance $\ell$ to ship the goods and has to travel another $\ell$ distance to return with an empty load. For the vehicle only, the variable cost is the total fuel consumption $\left(2 \ell f_{e}\right)$ times the fuel price $(\alpha)$. An additional variable cost is estimated for one-way distance $\ell$ based on the vehicle load, that is, a one-way distance $(\ell)$ multiplied by the fuel consumption per ton of payload $\left(c_{p}\right)$, product weight $\left(w_{p}\right)$, order quantity per trip $\left(\frac{\Omega}{N_{t}}\right)$, and fuel price $(\alpha)$. Similarly, the carbon emission cost for the vehicle is $2 \ell$ times the cost of carbon emission per unit distance of delivery $\left(c_{e}\right)$, and the carbon emission cost based on the load is $\ell$ times the cost of carbon emission per unit item per unit distance of delivery $\left(c_{k}\right)$ times $\left(\frac{\Omega}{N_{t}}\right)$. Thus, the total transportation cost per cycle is

$$
\begin{gathered}
T C=N_{t}\left[F_{C}+\left(2 \ell f_{e} \alpha+\frac{\ell c_{p} w_{p} \Omega \alpha}{N_{t}}\right)+\left(2 \ell c_{e}+\frac{\ell c_{k} \Omega}{N_{t}}\right)\right] \\
T C=F_{C} N_{t}+2 \ell f_{e} \alpha N_{t}+\ell c_{p} w_{p} \Omega \alpha+2 \ell c_{e} N_{t}+\ell c_{k} \Omega
\end{gathered}
$$

(e) Instalment capital cost:

The instalment capital cost is estimated following the procedure described by $[35,43]$ :

$$
\begin{aligned}
I C & =\left(\frac{\phi \delta \omega}{n} \Omega \times n \times \frac{\kappa}{n}\right)+\left(\frac{\phi \delta \omega}{n} \Omega \times(n-1) \times \frac{\kappa}{n}\right)+\cdots+\left(\frac{\phi \delta \omega}{n} \Omega \times(n-(n-1)) \times \frac{\kappa}{n}\right) \\
& =\left(\frac{\phi \delta \omega}{n} \Omega \times \frac{\kappa}{n}\right)(n+(n-1)+\cdots+2+1)=\left(\frac{\phi \delta \omega}{n} \Omega \times \frac{\kappa}{n}\right) \frac{n(n+1)}{2} \\
& =\frac{(n+1)}{2 n} \phi \delta \omega \Omega \kappa
\end{aligned}
$$

(f) Discount on purchase cost:

For the retailer's advanced payment on the purchase cost, the supplier provides $v \%$ discount. The discount rate $\xi$ depends on the number of instalments $n$; that is, the supplier offers a lower discount rate for more installments as follows:

$$
\xi=\frac{v}{n}, \quad 0 \leq v \leq 100
$$

Hence, the total discount is

$$
D C=\Omega \omega \xi=\frac{\Omega \omega v}{n} .
$$

\section{(g) Carbon emission reduction cost:}

The effort of carbon emission reduction needs an investment. The higher emission reduction needs an increasingly accelerated emission reduction cost. This cost is estimated according to Swami and Shah [42] in Equation (11).

$$
R C=\chi R_{C}^{2}
$$

(h) Sales revenue per cycle:

$$
S R=p \int_{0}^{T_{C}} D_{L} d t=p D_{L} T_{C}
$$




\subsubsection{Total Profit per Unit Time}

Now, for the total profit per unit time, one can write:

$$
\begin{aligned}
& \tau\left(p, T_{C}\right)=\frac{1}{T_{C}}(S R-O C-H C-P C-T C-I C-R C+D C)
\end{aligned}
$$

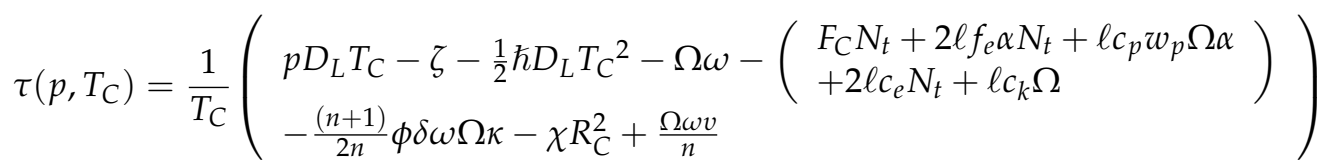

$$
\begin{aligned}
& \tau\left(p, T_{C}\right)=\frac{1}{T_{C}}\left(p D_{L} T_{C}-\frac{1}{2} \hbar D_{L} T_{C}^{2}-\left(\begin{array}{c}
\zeta+\Omega \omega+\frac{(n+1)}{2 n} \phi \delta \omega \Omega \kappa+F_{C} N_{t}+2 \ell f_{e} \alpha N_{t} \\
+\ell c_{p} w_{p} \Omega \alpha+2 \ell c_{e} N_{t}+\ell c_{k} \Omega+\chi R_{C}^{2}-\frac{\Omega \omega v}{n}
\end{array}\right)\right) \\
& \tau\left(p, T_{C}\right)=\frac{1}{T_{C}}\left(p\left(\psi-\gamma p+\eta R_{C}\right) T_{C}-\frac{1}{2} \hbar\left(\psi-\gamma p+\eta R_{C}\right) T_{C}^{2}-\lambda_{1}\right)
\end{aligned}
$$

where

$$
\lambda_{1}=\zeta+\Omega \omega+\frac{(n+1)}{2 n} \phi \delta \omega \Omega \kappa+F_{C} N_{t}+2 \ell f_{e} \alpha N_{t}+\ell c_{p} w_{p} \Omega \alpha+2 \ell c_{e} N_{t}+\ell c_{k} \Omega+\chi R_{C}^{2}-\frac{\Omega \omega v}{n}
$$

\subsection{Case II: With Advanced Payment and a Discount for Single Time Payment}

In this case, the retailer has to pay in advance in a single payment. The payment amount means the whole purchase cost. The scenario is described in Figure 2, which is a modified version of Figure 1.

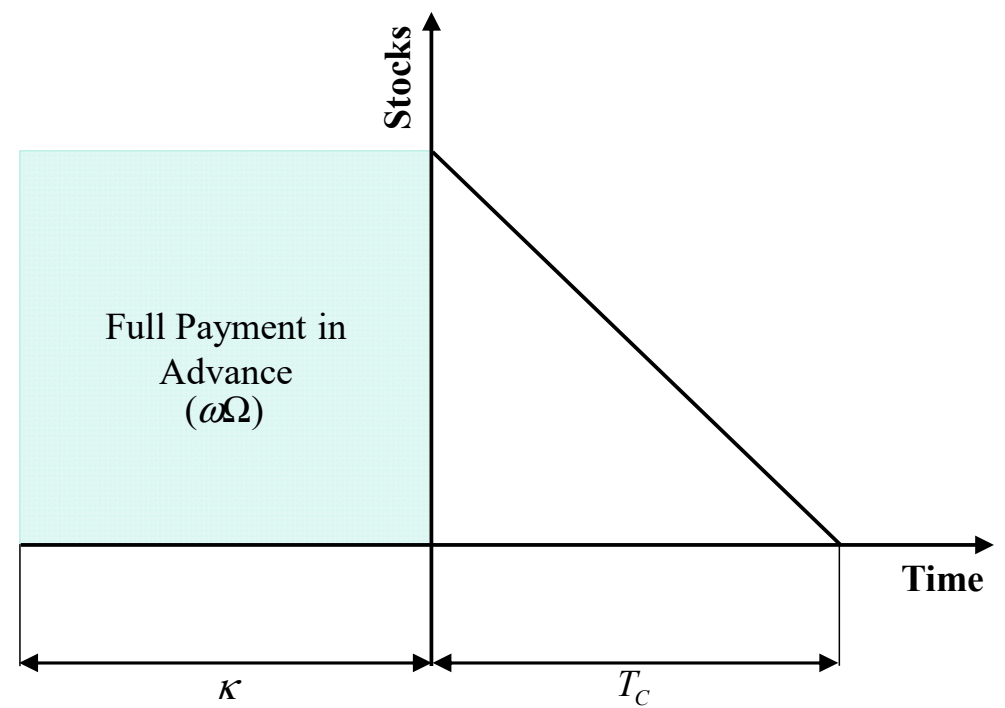

Figure 2. Graphical presentation of the inventory system for Case II.

The supplier offers a $v \%$ discount to the retailer for a single-time prepayment as a benefit. In this situation, the retailer may have a crisis of capital during time $\kappa$; in that case, a loan with some interest of $\phi_{L} \%$ from any financial institutes or other funds can be a suitable option to manage the required capital.

The discount for purchase cost is

$$
P C=(1-v) \Omega \omega .
$$

The associated cost of taking a loan is

$$
L C=\phi_{L} \kappa(1-v) \Omega \omega .
$$


Hence, the total profit per unit time can be written as:

$$
\begin{gathered}
\tau_{f}\left(p, T_{C}\right)=\frac{1}{T_{C}}(S R-O C-H C-P C-T C-R C-L C) \\
\tau_{f}\left(p, T_{C}\right)=\frac{1}{T_{C}}\left(\begin{array}{c}
p D_{L} T_{C}-\zeta-\frac{1}{2} \hbar D_{L} T_{C}{ }^{2}-(1-v) \Omega \omega \\
-\left(\begin{array}{c}
F_{C} N_{t}+2 \ell f_{e} \alpha N_{t}+\ell c_{p} w_{p} \Omega \alpha \\
+2 \ell c_{e} N_{t}+\ell c_{k} \Omega
\end{array}\right)-\chi R_{C}^{2}-\phi_{L} \kappa(1-v) \Omega \omega
\end{array}\right) \\
\tau_{f}\left(p, T_{C}\right)=\frac{1}{T_{C}}\left(p\left(\psi-\gamma p+\eta R_{C}\right) T_{C}-\frac{1}{2} \hbar\left(\psi-\gamma p+\eta R_{C}\right) T_{C}^{2}-\lambda_{2}\right)
\end{gathered}
$$

where

$$
\lambda_{2}=\zeta+\left(1+\phi_{L} \kappa\right)(1-v) \Omega \omega+F_{C} N_{t}+2 \ell f_{e} \alpha N_{t}+\ell c_{p} w_{p} \Omega \alpha+2 \ell c_{e} N_{t}+\ell c_{k} \Omega+\chi R_{C}^{2}
$$

\subsection{Case III: Without Advanced Payment}

In this case, the retailer does not pay in advance. If the retailer does not pay any payment in advance, then there is no instalment cost and discount. Thus, there is a necessity to modify Figure 1 into Figure 3 . The retailer must pay the full payment during purchase product shipment.

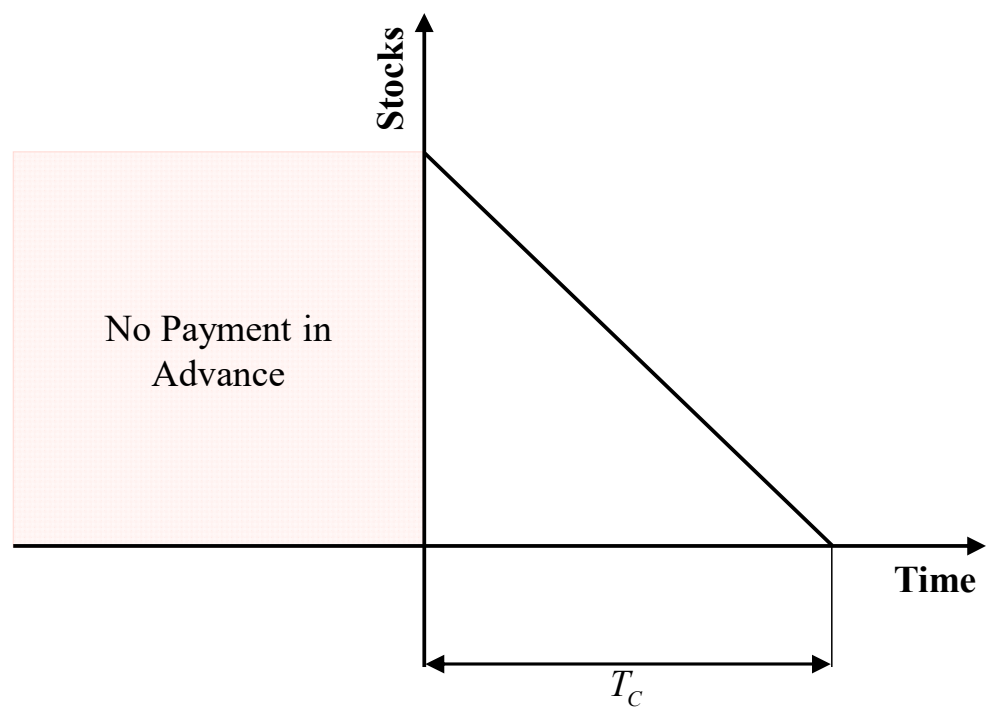

Figure 3. Graphical presentation of the inventory system for Case III.

Then, the total profit per unit time can be written as:

$$
\begin{gathered}
\tau_{N}\left(p, T_{C}\right)=\frac{1}{T_{C}}(S R-O C-H C-P C-T C-R C) \\
\tau_{N}\left(p, T_{C}\right)=\frac{1}{T_{C}}\left(p D_{L} T_{C}-\zeta-\frac{1}{2} \hbar D_{L} T_{C}^{2}-\Omega \omega-\left(\begin{array}{c}
F_{C} N_{t}+2 \ell f_{e} \alpha N_{t}+\ell c_{p} w_{p} \Omega \alpha \\
+2 \ell c_{e} N_{t}+\ell c_{k} \Omega
\end{array}\right)-\chi R_{C}^{2}\right) \\
\tau_{N}\left(p, T_{C}\right)=\frac{1}{T_{C}}\left(p\left(\psi-\gamma p+\eta R_{C}\right) T_{C}-\frac{1}{2} \hbar\left(\psi-\gamma p+\eta R_{C}\right) T_{C}^{2}-\lambda_{3}\right)
\end{gathered}
$$

where

$$
\lambda_{3}=\zeta+\Omega \omega+F_{C} N_{t}+2 \ell f_{e} \alpha N_{t}+\ell c_{p} w_{p} \Omega \alpha+2 \ell c_{e} N_{t}+\ell c_{k} \Omega+\chi R_{C}^{2}
$$

\section{Theoretical Development}

Here, the concavity of the profit function is analyzed to show the existence of an optimal solution for each case. 


\subsection{Case I (with Advanced Payment and a Discount for Instalment Based Payment)}

It is now important to investigate the concavity nature of the profit function $\tau\left(p, T_{C}\right)$ in Equation (13) for Case I. For this purpose, the priority is to determine the critical points, and one needs to differentiate Equation (13) with respect to the two decision variables $p, T_{C}$ as follows:

$$
\begin{gathered}
\frac{\partial \tau}{\partial T_{C}}=-\frac{1}{T_{C}^{2}}\left[\frac{1}{2} \hbar\left(\psi-\gamma p+\eta R_{C}\right) T_{C}^{2}-\lambda_{1}\right] \\
\frac{\partial \tau}{\partial p}=\psi-2 \gamma p+\eta R_{C}+\frac{1}{2} \hbar \gamma T_{C}
\end{gathered}
$$

The critical points can be determined by setting Equations (21) and (22) to zero and doing some manipulations.

$$
\begin{gathered}
T_{C}^{*}=\sqrt{\frac{2 \lambda_{1}}{\hbar\left(\psi-\gamma p+\eta R_{C}\right)}} \\
p^{*}=\frac{1}{2 \gamma}\left(\psi+\eta R_{C}+\frac{1}{2} \hbar \gamma T_{C}\right)
\end{gathered}
$$

The concavity of the profit function is next discussed with some conditions.

Proposition 1. The profit function $\tau\left(p, T_{C}\right)$ in Equation (13) is concave regarding the replenishment time $T_{C}$ if the selling price $p$ remains fixed, and hence it provides a unique optimal $T_{C}^{*}$.

Proof. One needs to determine the associated critical points as well as prove the sufficient condition to confirm the concavity of the profit function. The critical point is associated with Equation (23).

$$
T_{C}^{*}=\sqrt{\frac{2 \lambda_{1}}{\hbar\left(\psi-\gamma p+\eta R_{C}\right)}}
$$

Then, differentiating the profit function as in Equation (13) with respect to $T_{C}$, one can find:

$$
\frac{\partial^{2} \tau}{\partial T_{C}^{2}}=-\frac{2 \lambda_{1}}{T_{C}^{3}}
$$

Since $\lambda_{1}>0$ and replenishment time $T_{C}$ must be positive, $\frac{\partial^{2} \tau}{\partial T_{C}^{2}}<0$. Thus, we confirm the concave nature of the profit function regarding $T_{C}$, and the critical point $T_{C}$ becomes the unique optimal point $T_{C}^{*}$

Proposition 2. The profit function $\tau\left(p, T_{C}\right)$ in Equation (13) is concave regarding the replenishment time $p$ if the selling price $p$ remains fixed, and hence it provides a unique optimal $p^{*}$.

Proof. The solution system is akin to the proposed system of Proposition 1; thus, to avoid redundancy the proof is removed.

Proposition 3. The profit function $\tau\left(p, T_{C}\right)$ of selling price $p$ and replenishment time $T_{C}$ in Equation (13) is a strictly pseudo-concave function at a unique optimal investment $\left(p^{*}, T_{C}^{*}\right)$.

Proof. The Hessian matrix of $\tau\left(p, T_{C}\right)$ is of order $2 \times 2$.

$$
\Delta=\left[\begin{array}{ll}
\frac{\partial^{2} \tau\left(p, T_{C}\right)}{\partial T_{C}^{2}} & \frac{\partial^{2} \tau\left(p, T_{C}\right)}{\partial T_{C} \partial p} \\
\frac{\partial^{2} \tau\left(p, T_{C}\right)}{\partial p \partial T_{C}} & \frac{\partial^{2} \tau\left(p, T_{C}\right)}{\partial p^{2}}
\end{array}\right]
$$


To prove that $\tau\left(p, T_{C}\right)$ is a strictly pseudo-concave function, it is essential to confirm that the Hessian matrix $\Delta$ is negative definite. Thus, it is necessary to show that the leading principal minors, $(-1)^{k} \Delta_{k}>0,1 \leq k \leq 2$ means the first principal minor $\Delta_{1}$ is negative, and the second principle minor $\Delta_{2}$ is positive.

$$
\Delta_{1}=\left|\frac{\partial^{2} \tau\left(p, T_{C}\right)}{\partial T_{C}^{2}}\right|=\frac{\partial^{2} \tau\left(p, T_{C}\right)}{\partial T_{C}^{2}}
$$

and

$$
\Delta_{2}=\left|\begin{array}{ll}
\frac{\partial^{2} \tau\left(p, T_{C}\right)}{\partial T_{C}^{2}} & \frac{\partial^{2} \tau\left(p, T_{C}\right)}{\partial T_{C} \partial p} \\
\frac{\partial^{2} \tau\left(p, T_{C}\right)}{\partial p \partial T_{C}} & \frac{\partial^{2} \tau\left(p, T_{C}\right)}{\partial p^{2}}
\end{array}\right|=\frac{\partial^{2} \tau\left(p, T_{C}\right)}{\partial T_{C}^{2}} \frac{\partial^{2} \tau\left(p, T_{C}\right)}{\partial p^{2}}-\frac{\partial^{2} \tau\left(p, T_{C}\right)}{\partial p \partial T_{C}} \frac{\partial^{2} \tau\left(p, T_{C}\right)}{\partial T_{C} \partial p}
$$

Taking the second order partial derivatives of the profit function $\tau\left(p, T_{C}\right)$ in Equation (13) with respect to $p$ and $T_{C}$, one gets

$$
\begin{gathered}
\frac{\partial^{2} \tau}{\partial T_{C}^{2}}=-\frac{2 \lambda_{1}}{T_{C}^{3}} \\
\frac{\partial^{2} \tau}{\partial p^{2}}=-2 \gamma \\
\frac{\partial^{2} \tau}{\partial T_{C} \partial p}=\frac{1}{2} \hbar \gamma
\end{gathered}
$$

Proposition 1 ensures that the first principal minor $\Delta_{1}$ is negative at the optimal point $p=p^{*}$ and $T_{C}=T_{C}^{*}$. Now, the only target should be to prove that the second principal minor $\Delta_{2}$ is positive and to aim it, after manipulations, one can write:

$$
\Delta_{2}=\frac{4 \gamma \lambda_{1}}{T_{C}^{3}}-\frac{1}{4} \hbar^{2} \gamma^{2}
$$

At the optimal point $p=p^{*}$ and $T_{C}=T_{C^{\prime}}^{*}$

$$
\Delta_{2}=\frac{4 \gamma \hbar_{1}}{T_{C}^{* 3}}-\frac{1}{4} \hbar^{2} \gamma^{2}
$$

Later, Lemma 1 confirms the fact that $\Delta_{2}>0$.

Thus, the proof of Proposition 3 is complete such that $\tau\left(p, T_{C}\right)$ is a strictly pseudoconcave function at a unique optimal investment $\left(p^{*}, T_{C}^{*}\right)$. Hence, the profit function affirms the global maximum solution at $\left(p^{*}, T_{C}^{*}\right)$.

Lemma 1. If replenishment time $T_{C}<\left(\frac{16 \lambda_{1}}{\hbar^{2} \gamma}\right)^{\frac{1}{3}}$, then Equation (32) provides positive results, which consequently shows that Proposition 3 is valid.

Proof. Replenishment time $T_{C}<\left(\frac{16 \lambda_{1}}{\hbar^{2} \gamma}\right)^{\frac{1}{3}}$

$$
\begin{gathered}
\hbar^{2} \gamma<\frac{16 \lambda_{1}}{T_{C}^{3}} \\
\hbar^{2} \gamma \frac{\gamma}{4}<\frac{16 \lambda_{1}}{T_{C}^{3}} \frac{\gamma}{4}[\text { since } \gamma>0]
\end{gathered}
$$




$$
\begin{gathered}
\frac{1}{4} \hbar^{2} \gamma^{2}<\frac{4 \gamma \lambda_{1}}{T_{C}^{3}} \\
\frac{4 \gamma \lambda_{1}}{T_{C}^{* 3}}-\frac{1}{4} \hbar^{2} \gamma^{2}>0
\end{gathered}
$$

Thus, $\Delta_{2}>0$

\subsection{Case II: With Advanced Payment and a Discount for Single Time Payment}

The concavity test for Case II is similar to Case I, so the proof for Case II is not shown to avoid redundancy. From Equations (13) and (17) one has:

$$
\begin{gathered}
\tau\left(p, T_{C}\right)=\frac{1}{T_{C}}\left(p\left(\psi-\gamma p+\eta R_{C}\right) T_{C}-\frac{1}{2} \hbar\left(\psi-\gamma p+\eta R_{C}\right) T_{C}^{2}-\lambda_{1}\right) \\
\tau_{f}\left(p, T_{C}\right)=\frac{1}{T_{C}}\left(p\left(\psi-\gamma p+\eta R_{C}\right) T_{C}-\frac{1}{2} \hbar\left(\psi-\gamma p+\eta R_{C}\right) T_{C}{ }^{2}-\lambda_{2}\right)
\end{gathered}
$$

where

$$
\begin{aligned}
& \lambda_{1}=\zeta+\Omega \omega+\frac{(n+1)}{2 n} \phi \delta \omega \Omega \kappa+F_{C} N_{t}+2 \ell f_{e} \alpha N_{t}+\ell c_{p} w_{p} \Omega \alpha+2 \ell c_{e} N_{t}+\ell c_{k} \Omega+\chi R_{C}^{2}-\frac{\Omega \omega v}{n} \\
& \lambda_{2}=\zeta+\left(1+\phi_{L} \kappa\right)(1-v) \Omega \omega+F_{C} N_{t}+2 \ell f_{e} \alpha N_{t}+\ell c_{p} w_{p} \Omega \alpha+2 \ell c_{e} N_{t}+\ell c_{k} \Omega+\chi R_{C}^{2}
\end{aligned}
$$

From $\tau\left(p, T_{C}\right)$ and $\tau_{f}\left(p, T_{C}\right)$ one can easily notice that parts $\left(\lambda_{1}\right.$ and $\left.\lambda_{2}\right)$ are the only difference between these two profit functions. Moreover, these two parts $\left(\lambda_{1}\right.$ and $\left.\lambda_{2}\right)$ are independent of decision variables $\left(p, T_{C}\right)$. Thus, there will be no change in making a decision regarding the concavity of these profit functions. However, in the numerical example, the concavity is presented numerically.

\subsection{Case III: Without Advanced Payment}

From Equations (13) and (19), one has:

$$
\begin{gathered}
\tau\left(p, T_{C}\right)=\frac{1}{T_{C}}\left(p\left(\psi-\gamma p+\eta R_{C}\right) T_{C}-\frac{1}{2} \hbar\left(\psi-\gamma p+\eta R_{C}\right) T_{C}^{2}-\lambda_{1}\right) \\
\tau_{N}\left(p, T_{C}\right)=\frac{1}{T_{C}}\left(p\left(\psi-\gamma p+\eta R_{C}\right) T_{C}-\frac{1}{2} \hbar\left(\psi-\gamma p+\eta R_{C}\right) T_{C}^{2}-\lambda_{3}\right)
\end{gathered}
$$

where

$$
\begin{gathered}
\lambda_{1}=\zeta+\Omega \omega+\frac{(n+1)}{2 n} \phi \delta \omega \Omega \kappa+F_{C} N_{t}+2 \ell f_{e} \alpha N_{t}+\ell c_{p} w_{p} \Omega \alpha+2 \ell c_{e} N_{t}+\ell c_{k} \Omega+\chi R_{C}^{2}-\frac{\Omega \omega v}{n} \\
\lambda_{3}=\zeta+\Omega \omega+F_{C} N_{t}+2 \ell f_{e} \alpha N_{t}+\ell c_{p} w_{p} \Omega \alpha+2 \ell c_{e} N_{t}+\ell c_{k} \Omega+\chi R_{C}^{2}
\end{gathered}
$$

The whole scenario of this case is similar to the previous Case II. Therefore, there will be no change in decision-making as in Case II. However, the concavity of the profit function is presented in the numerical example section.

\section{Analysis and Discussion}

\subsection{Case Study}

The choice of eco-friendly products is a growing trend that is being adopted by millions of people. A new addition in this category is an eco-friendly microwave oven (Figure 4), which draws the attention of business owners and customers. The higher the eco-friendliness, the higher the demand; although sometimes the price is slightly elevated, it satisfies all purposes of customers. A retailer who does not have enough capital can 
advance some purchase costs to the supplier to book the products. The supplier, in return, provides numerous discount amounts for him according to the retailer's payment. A case from a retailer shop is visited to fit in our model. The proposed problem is discussed with the shop manager, and he is asked to provide actual data accordingly. Those data are used in later numerical sections to validate the model and maintain a relationship with the data of the previously published article.

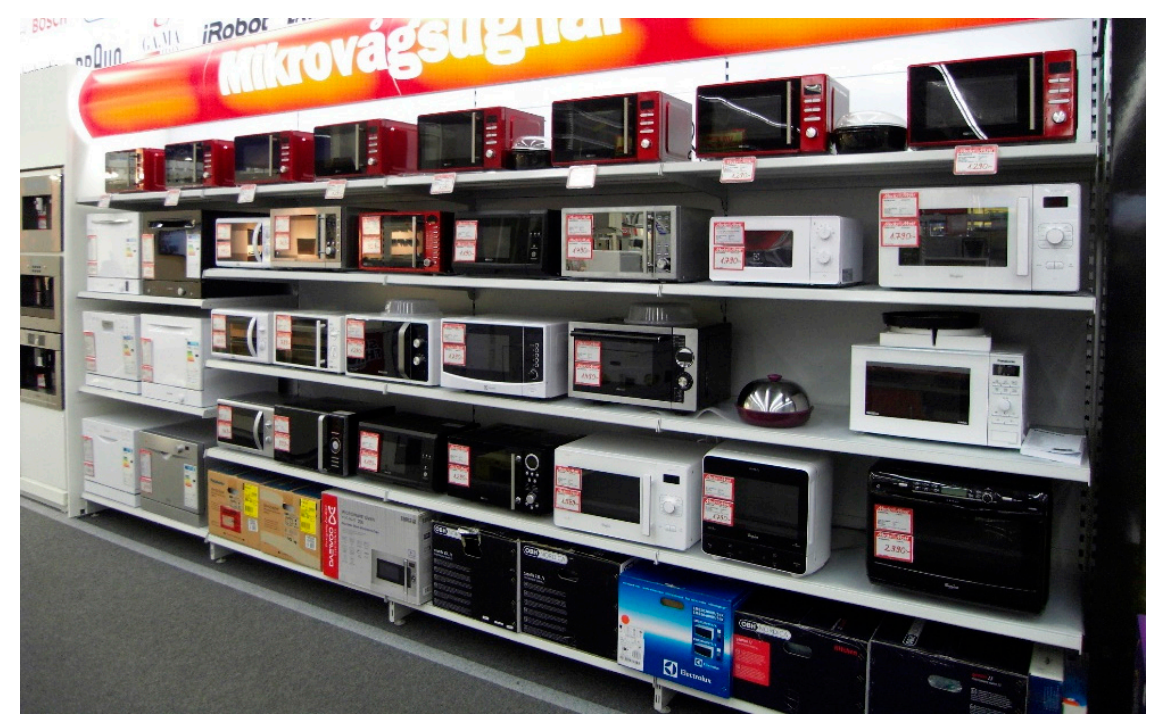

Figure 4. A retail shop of microwave oven. (Source: https://upload.wikimedia.org/wikipedia/ commons/7/7e/Microwave_ovens\%2C_Media_Markt\%2C_Svagertorp\%2C_Malmo.JPG, accessed on 26 December 2021).

\subsection{Numerical Illustration}

Here, we present three examples. We have collected secondary data from different published articles.

Example 1. (Case III) In the first example, green carbon emission costs are considered with no payment in advance. For numerical illustration, the following parameters are considered: ordering costs per order placement $\xi=\$ 1000 /$ cycle, the demand combined with market potential $\Psi=220$, price sensitivity coefficient $\gamma=0.65$, low carbon preference coefficient $\eta=2$, and manufacturer's carbon emission reduction level $R_{c}=0.5$, carbon emission reduction investment $\chi=\$ 800$. The purchase cost per unit $\omega=\$ 150$, per unit holding cost $h=\$ 2$. Further, the fixed cost per trip $F_{c}=\$ 200 /$ trip, number of trips $N_{t}=3$, fuel price $\alpha=\$ 0.3 /$ liter, the empty vehicle fuel consumption $f_{c}=1$ liter, travelled distance $l=100 \mathrm{~km}$, product weight $w_{p}=0.5 \mathrm{~kg}$, fuel consumption per ton of payload $C_{p}=1.5$ liter/ton, carbon emission cost per unit distance $c_{e}=\$ 0.03 / \mathrm{km}$, and carbon emission cost per unit item per unit distance $c_{k}=\$ 0.02 /$ unit $/ \mathrm{km}$.

We obtain optimal solutions per unit selling price $p^{*}=\$ 260.36$, replenishment time $T_{C}^{*}=6.21$ months, order quantity $\Omega=321.61$ units, and total profit $\tau_{N}=\$ 3801.423$ using Lingo 19 software with the aid of an exact optimization approach.

If we consider manufacturer's carbon emission reduction level $\left(R_{c}\right)$ and selling price $(p)$ as decision variables and cycle time $\left(T_{C}=6.21\right.$ months $)$ as constant, then, we obtain the optimal solutions, per unit selling price $p^{*}=\$ 260.54$, manufacturer's carbon emission reduction level $R_{c}^{*}=0.62$, order quantity $\Omega=322.23$ units, and total profit $\tau_{N}=\$ 3803.25$.

Again, if we consider that manufacturer's carbon emission reduction level $\left(R_{c}\right)$ and cycle time $\left(T_{C}\right)$ are decision variables and selling price $(p=\$ 260.35)$ is constant, then we obtain the optimal solutions, manufacturer's carbon emission reduction level $R_{c}^{*}=0.63$, cycle time $T_{C}^{*}=6.38$ months, order quantity $\Omega=332.11$ units, and total profit $\tau_{N}=\$ 3803.438$. 
From Figure 5, one can easily observe that the total profit function confirms the concavity nature in terms of the two decision variables, and the optimum profit is located at the blue dot point.

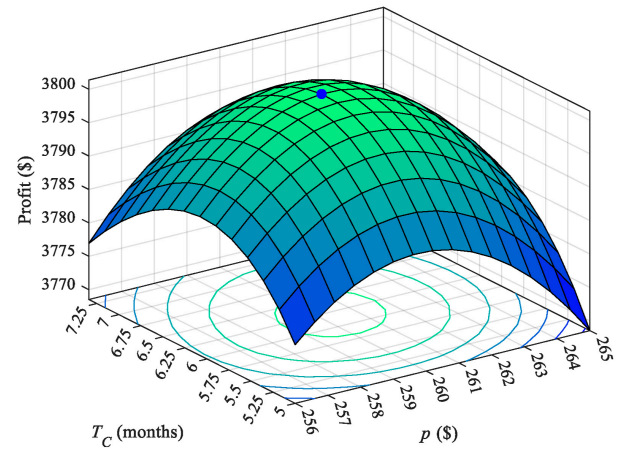

(a)

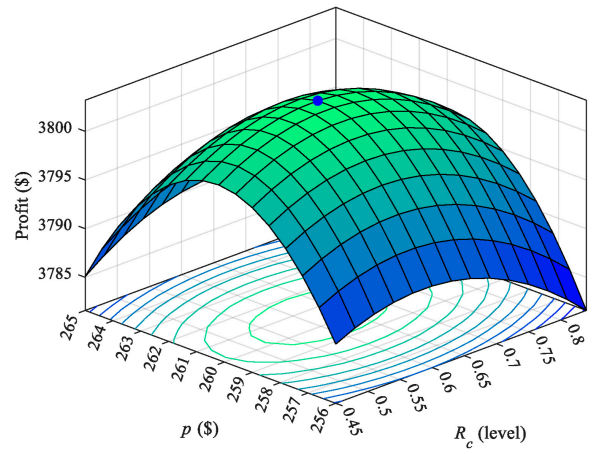

(b)

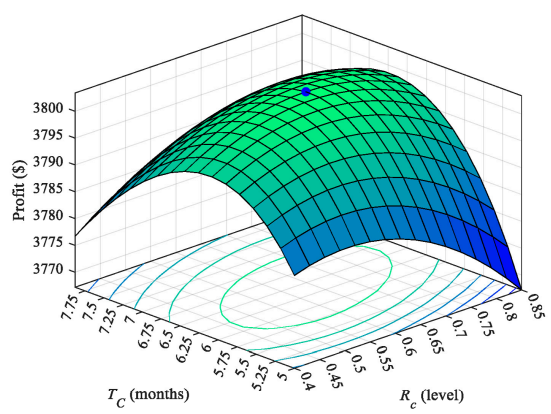

(c)

Figure 5. Profit function $(\tau)$ with regard to: $(\mathbf{a})$ the selling price $(p)$ and cycle time $\left(T_{C}\right)$; $(\mathbf{b})$ the manufacturer's carbon emission reduction level $\left(R_{c}\right)$ and selling price $(p)$; $(\mathbf{c})$ the manufacturer's carbon emission reduction level $\left(R_{c}\right)$ and cycle time $\left(T_{C}\right)$.

When selling price $(p)$, cycle time $\left(T_{C}\right)$, and manufacturer's carbon emission reduction level $\left(R_{c}\right)$ are decision variables, then optimal solutions are per-unit selling price $p^{*}=\$ 260.66$, cycle time $T_{C}^{*}=6.40$ months, and manufacturer's carbon emission reduction level $R_{c}^{*}=0.638$, order quantity $\Omega=331.82$ units, and total profit $\tau_{N}=\$ 3803.499$.

Figure 6 shows that the profit function increases with respect to the increased selling price $(p)$, cycle time $\left(T_{C}\right)$, and manufacturer's carbon emission reduction level $\left(R_{c}\right)$, and the profit function becomes optimum for optimum selling price $p^{*}=\$ 260.66$, optimum cycle time $T_{c}=6.40$ months, and manufacturer's carbon emission reduction level $R_{c}^{*}=0.638$. After the optimum point indicated by the green star marker, the profit function decreases, although the selling price and the cycle time increase. This behavior also confirms the concavity nature of the profit function.

Example 2. (Case II) All the parameters are the same as in Example 1. For a single payment model, the supplier offers $v=5 \%$. Further, the length of time during prepayment $\kappa=0.5$ years and retailer interest rate of loan from any financial institutes $\phi_{L}=3 \%$.

We obtain the optimal solutions, per unit selling price $p^{*}=\$ 257.62$, replenishment time $T_{C}^{*}=6.11$ months, order quantity $\Omega=327.08$ units, and total profit $\tau_{f}=\$ 4083.795$.

If we consider manufacturer's carbon emission reduction level $\left(R_{c}\right)$ and selling price $(p)$ as decision variables and cycle time $\left(T_{C}=6.12\right.$ months $)$ as constant, then we obtain the optimal solutions of per-unit selling price $p^{*}=\$ 257.83$, manufacturer's carbon emission reduction level $R_{c}^{*}=0.63$, order quantity $\Omega=328.48$ units, and total profit $\tau_{N}=\$ 4086.035$.

Again, if we consider manufacturer's carbon emission reduction level $\left(R_{c}\right)$ and cycle time $\left(T_{C}\right)$ as decision variables and selling price $(p=\$ 257.62)$ as constant, then we obtain 
the optimal solutions as manufacturer's carbon emission reduction level $R_{c}^{*}=0.65$, cycle time $T_{C}^{*}=6.29$ months, order quantity $\Omega=338.84$ units, and total profit $\tau_{N}=\$ 4086.235$.

When selling price $(p)$, cycle time $\left(T_{C}\right)$, and manufacturer's carbon emission reduction level $\left(R_{c}\right)$ are decision variables, then optimal solutions are per-unit selling price $p^{*}=\$ 257.96$, cycle time $T_{C}^{*}=6.31$ months, and manufacturer's carbon emission reduction level $R_{c}^{*}=0.65$, order quantity $\Omega=338.54$ units, and total profit $\tau_{N}=\$ 4086.305$.

For this example, Figure 7 confirms the concavity nature of the profit function with respect to the two decision variables.

Figure 8a shows that the profit declines due to growing lead time. Figure $8 \mathrm{~b}$ confirms that the higher discount rate produces the higher profit gaining, and Figure 8c confirms that the total profit declines for the higher interest rate on the loan amount to collect capital.

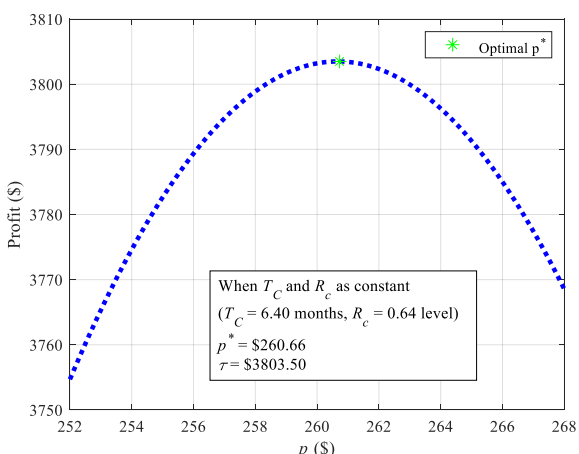

(a)

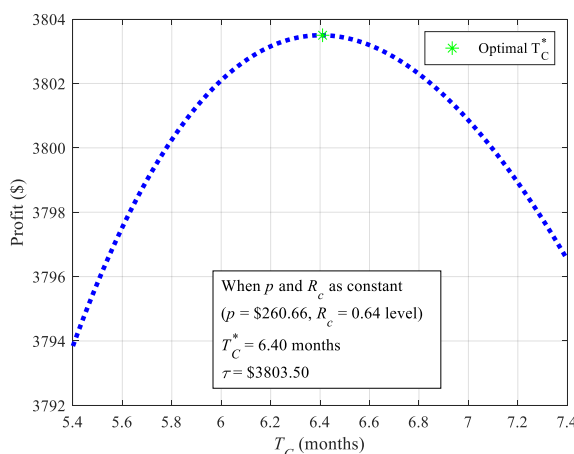

(b)

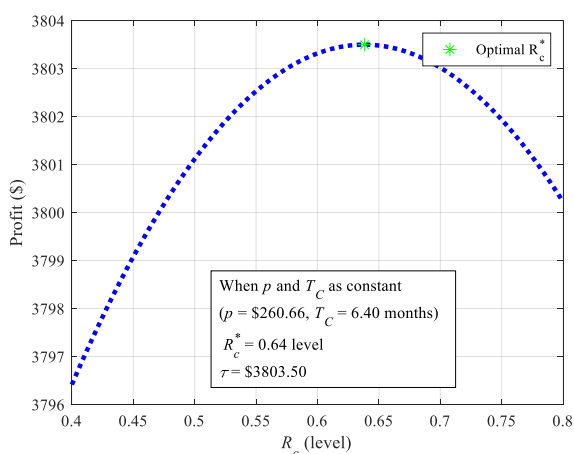

(c)

Figure 6. Profit function $(\tau)$ regarding (a) the selling price $(p) ;(\mathbf{b})$ cycle time $\left(T_{C}\right)$; (c) manufacturer's carbon emission reduction level $\left(R_{c}\right)$.

Example 3. (Case I) All the parameters are the same as Example 1. Some additional parameters are as follows: number of equal prepayments before receiving order quantity $n=10$, the portion of total purchase cost $\delta=0.8$, the interest rate of capital cost per year, length of time during which the prepayments are paid $\kappa=0.5$ years, and discount rate for prepayment $v=5 \%$.

We acquire the optimal solutions of per-unit selling price $p^{*}=\$ 276.86$, replenishment time $<\phi=1 \%$ months, order quantity $\Omega=286.35$ units, and total profit $\tau=\$ 2304.672$.

If we consider manufacturer's carbon emission reduction level $\left(R_{c}\right)$ and selling price $(p)$ as decision variables and cycle time $\left(T_{C}=6.21\right.$ months $)$ as constant, then we obtain the optimal solutions of per-unit selling price $p^{*}=\$ 276.45$, manufacturer's carbon emission reduction level $R_{c}^{*}=0.49$, order quantity $\Omega=256.35$ units, and total profit $\tau_{N}=\$ 2300.881$.

Again, if we consider manufacturer's carbon emission reduction level $\left(R_{c}\right)$ and cycle time $\left(T_{C}\right)$ as decision variables and selling price $(p=\$ 260.35)$ as constant, then we obtain the optimal solutions of manufacturer's carbon emission reduction level $R_{c}^{*}=0.36$, cycle time $T_{C}^{*}=6.08$ months, order quantity $\Omega=312.98$ units, and total profit $\tau_{N}=\$ 2134.147$. 
When selling price $(p)$, cycle time $\left(T_{C}\right)$, and manufacturer's carbon emission reduction level $\left(R_{c}\right)$ are decision variables, then optimal solutions are per-unit selling price $p^{*}=\$ 276.99$, cycle time $T_{C}^{*}=7.06$ months, and manufacturer's carbon emission reduction level $R_{c}^{*}=0.56$, order quantity $\Omega=289.92$ units, and total profit $\tau_{N}=\$ 2305.004$.

For this example, Figure 9 confirms the concavity nature of the profit function with respect to the two decision variables.

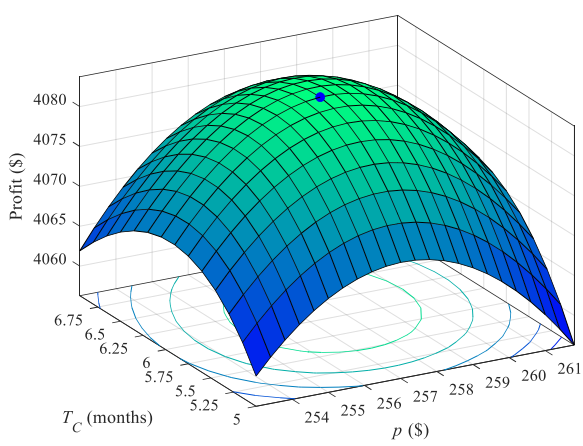

(a)

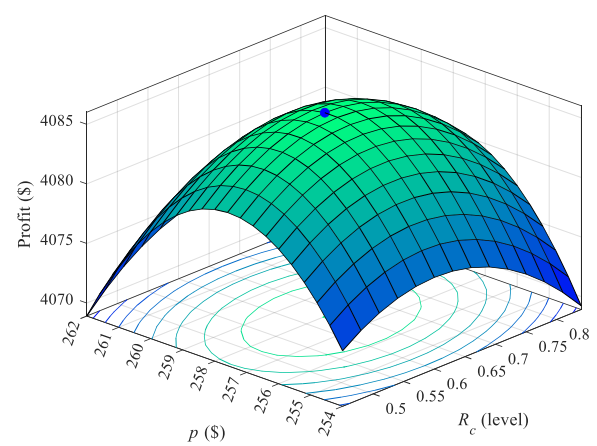

(b)

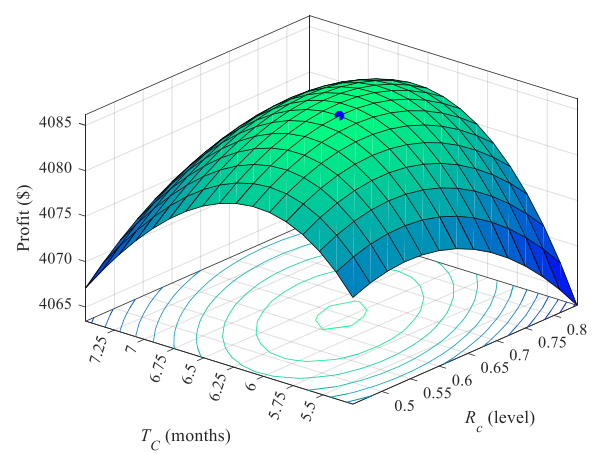

(c)

Figure 7. Profit function $(\tau)$ with regard to: $(\mathbf{a})$ the selling price $(p)$ and cycle time $\left(T_{C}\right)$; $(\mathbf{b})$ the manufacturer's carbon emission reduction level $\left(R_{c}\right)$ and selling price $(p)$; $(\mathrm{c})$ the manufacturer's carbon emission reduction level $\left(R_{c}\right)$ and cycle time $\left(T_{C}\right)$.

Figure 10a shows that the profit is higher for a smaller number of instalments and is smaller for a larger number of instalments. As the retailer has to pay interest for instalmentbased payment, the cost becomes higher, and the profit becomes lower. From Figure 10b, one can confirm that the higher lead time forces a lower profit to be gained. Figure 10c confirms that the total profit declines for higher portion payment in advance, whereas Figure 10d assures the fact that for a higher amount of discount rate for instalment payment in advance, the total profit increases.

\subsection{Sensitivity Analysis}

Table 2 shows the sensitivity analysis of the present work. One can easily observe the robustness among the parameters. For three cases, the test has been performed for the parameters within the range of $-20 \%$ to $+20 \%$.Some critical observations can be summarized based on the sensitivity table (Table 2):

a. The market potential $(\psi)$ is positively correlated with the integrated profit. The selling price is correlated similarly, but the cycle length interacts negatively. One can detect the continuous rise in profit and selling price with growing market potential $(\psi)$ for all these three cases, and the profit becomes maximum for Case II, whereas the selling price, as well as cycle length, become minimum. 
b. The total profit and selling price decline for all three cases as the price elasticity parameter $(\gamma)$ increases. The cycle length behaves in the opposite direction. One can observe the highest profit at the minimum value of the price elasticity parameter $(\gamma)$ for a discount on a single-instalment payment (Case II).

c. The total profit increases for all three cases with higher values of carbon emission reduction level $\left(R_{C}\right)$. The selling price and the cycle length show the same characteristics. The total profit is comparatively much lower in Case I as the instalment policy creates an extra cost. The profit is best in Case II, since the discount in purchasing cost influences higher profit gaining.

d. For all three cases, the ordering cost $(\zeta)$, as well as the holding cost $(\hbar)$, have a direct impact on total profit. The higher values of those two costs create a lower profit and vice versa. The increasing ordering charge or holding charge means a decline in profit. It is easy to observe the significant consequence of this fact for all three cases. A similar type of effect has been noted for fluctuations of the per-unit purchase cost $(\omega)$.

e. The larger the number of trips $\left(N_{t}\right)$ the lesser the profit becomes since an extra trip means it needs an additional fixed cost, variable cost, fuel, labor, etc. Therefore, the profit becomes lower for the intensifications of trips. The travel distance $(\ell)$, fuel cost $(\alpha)$, fuel consumption per ton of payload $\left(c_{p}\right)$, and product weight $\left(w_{p}\right)$ have similar impacts on profit as those can add additional expenses. Any longer distance brings additional cost in the expenses, so reduction of distance can optimize the profit, which is numerically true, as shown in the sensitivity table.

f. The implications of carbon emission cost on transportation cost have important roles in profit gaining. Increasing values of carbon emission cost per unit distance $\left(c_{e}\right)$ and carbon emission cost per unit item per unit distance $\left(c_{k}\right)$ force the total profit to be less in all three cases.

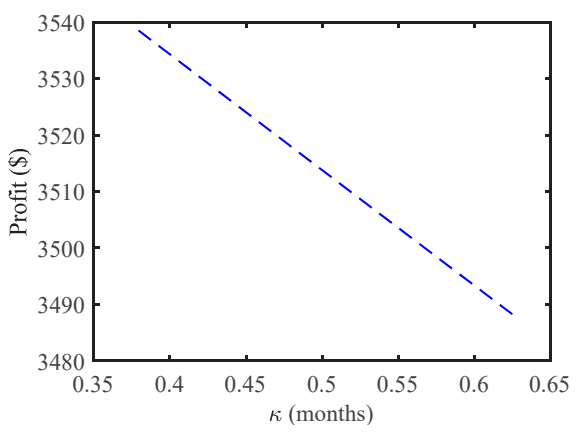

(a)

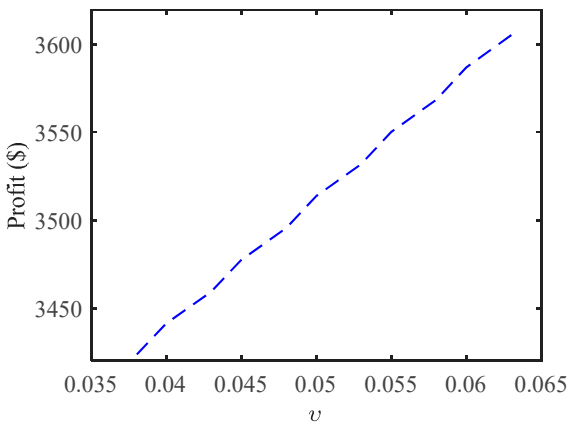

(b)

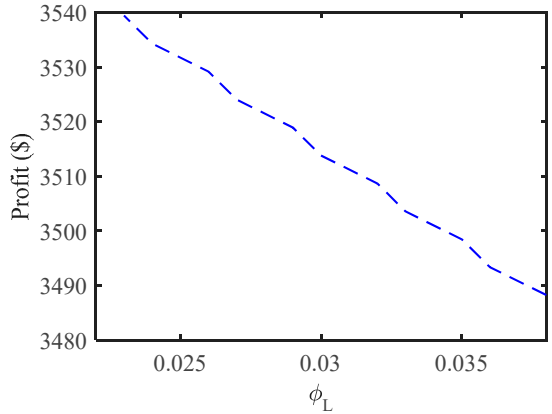

(c)

Figure 8. Total profit profile associated with single payment-based payment in advance parameters. (a) describes the total profit against different lead times, (b) describes the total profit for different discount rates due to instalment-based payment in advance, and (c) shows the profit vs. interest rate on the loan amount. 


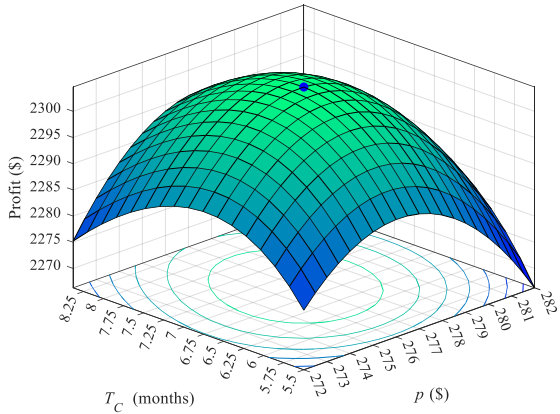

(a)

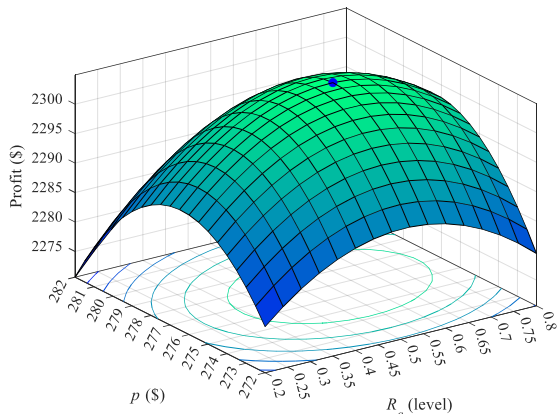

(b)

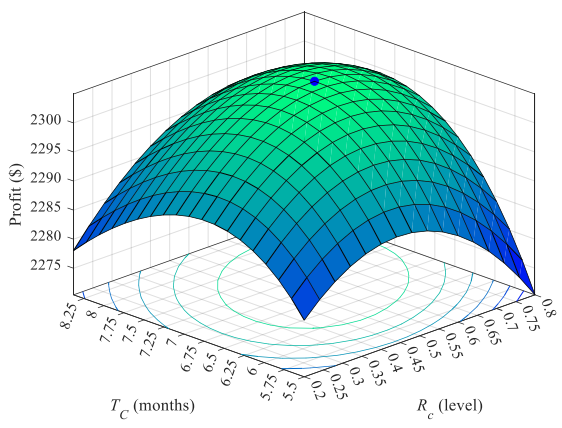

(c)

Figure 9. Profit function $(\tau)$ with regard to: $(\mathbf{a})$ the selling price $(p)$ and cycle time $\left(T_{C}\right) ;(\mathbf{b})$ the manufacturer's carbon emission reduction level $\left(R_{c}\right)$ and selling price $(p) ;(\mathbf{c})$ the manufacturer's carbon emission reduction level $\left(R_{c}\right)$ and cycle time $\left(T_{C}\right)$.

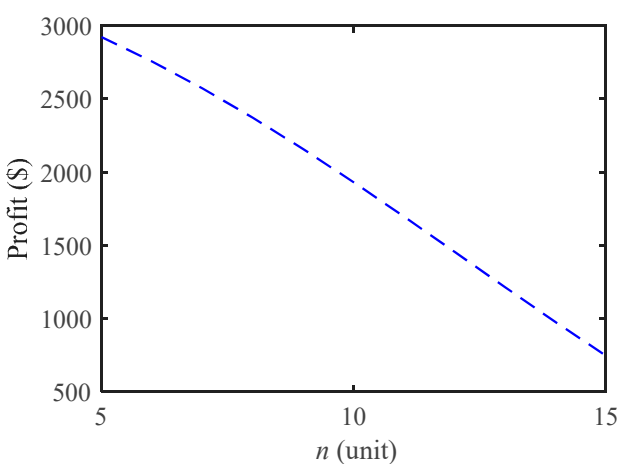

(a)

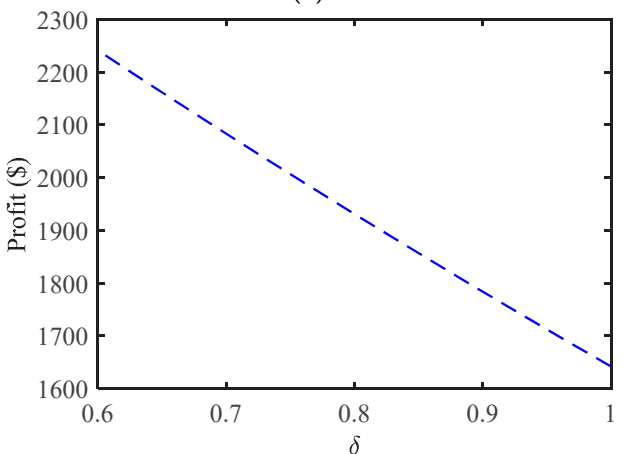

(c)

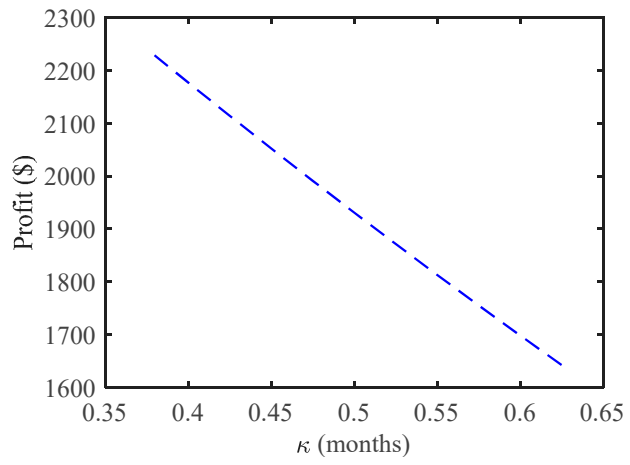

(b)

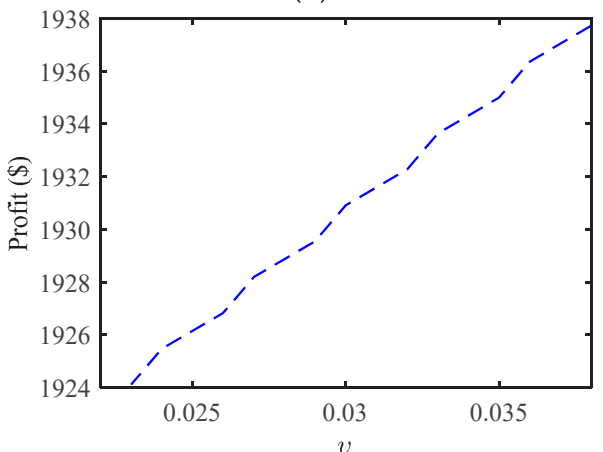

(d)

Figure 10. Total profit profile associated with instalment-based payment-in-advance parameters. (a) describes the total profit against the number of instalments, (b) shows the total profit for different lead times, (c) describes the profit vs. payment in advance portion, and (d) describes the total profit for different discount rates due to instalment based payment in advance. 
Table 2. Sensitivity Analysis.

\begin{tabular}{|c|c|c|c|c|c|c|c|c|c|c|c|}
\hline \multirow{2}{*}{$\begin{array}{l}\text { Parameter } \\
\text { (Base) }\end{array}$} & \multirow{2}{*}{$\begin{array}{c}\text { Change } \\
\text { in } \%\end{array}$} & \multirow{2}{*}{$\begin{array}{l}\text { Changed } \\
\text { Value }\end{array}$} & \multicolumn{3}{|c|}{ Case I } & \multicolumn{3}{|c|}{ Case II } & \multicolumn{3}{|c|}{ Case III } \\
\hline & & & $p$ & $T_{c}$ & Profit $\left(\tau_{N}\right)$ & $p$ & $T_{c}$ & Profit $\left(\tau_{f}\right)$ & $p$ & $T_{c}$ & Profit $(\tau)$ \\
\hline \multirow{4}{*}{$\psi(200)$} & $20 \%$ & 240.000 & 307.119 & 5.822 & 5033.220 & 288.058 & 5.311 & 7382.136 & 290.771 & 5.376 & 7020.964 \\
\hline & $10 \%$ & 220.000 & 290.755 & 6.428 & 3311.817 & 271.614 & 5.756 & 5278.759 & 274.336 & 5.839 & 4971.943 \\
\hline & $-10 \%$ & 180.000 & 258.518 & 8.618 & 893.981 & 238.977 & 7.150 & 2089.039 & 241.740 & 7.313 & 1891.779 \\
\hline & $-20 \%$ & 160.000 & 243.186 & 11.289 & 209.085 & 222.937 & 8.402 & 1007.654 & 225.755 & 8.676 & 866.120 \\
\hline \multirow{4}{*}{$\gamma(0.60)$} & $20 \%$ & 0.720 & 247.554 & 9.192 & 510.321 & 227.756 & 7.208 & 1636.208 & 230.539 & 7.411 & 1443.080 \\
\hline & $10 \%$ & 0.660 & 259.677 & 8.058 & 1090.069 & 240.206 & 6.729 & 2446.337 & 242.962 & 6.878 & 2223.500 \\
\hline & $-10 \%$ & 0.540 & 292.835 & 6.698 & 3116.149 & 273.686 & 6.012 & 4923.224 & 276.409 & 6.097 & 4641.829 \\
\hline & $-20 \%$ & 0.480 & 315.870 & 6.240 & 4772.288 & 296.810 & 5.732 & 6801.839 & 299.523 & 5.797 & 6491.457 \\
\hline \multirow{4}{*}{$\eta(2)$} & $20 \%$ & 2.400 & 274.676 & 7.269 & 1943.027 & 255.402 & 6.332 & 3529.771 & 258.138 & 6.443 & 3276.993 \\
\hline & $10 \%$ & 2.200 & 274.595 & 7.274 & 1936.966 & 255.320 & 6.336 & 3521.782 & 258.057 & 6.447 & 3269.278 \\
\hline & $-10 \%$ & 1.800 & 274.434 & 7.284 & 1924.869 & 255.157 & 6.342 & 3505.830 & 257.894 & 6.454 & 3253.873 \\
\hline & $-20 \%$ & 1.600 & 274.353 & 7.290 & 1918.833 & 255.075 & 6.346 & 3497.867 & 257.812 & 6.458 & 3246.183 \\
\hline \multirow{4}{*}{$\begin{array}{c}R_{C} \\
(0.50)\end{array}$} & $20 \%$ & 0.600 & 274.729 & 7.375 & 1935.516 & 255.447 & 6.424 & 3521.148 & 258.185 & 6.537 & 3268.518 \\
\hline & $10 \%$ & 0.550 & 274.621 & 7.325 & 1933.370 & 255.342 & 6.380 & 3517.653 & 258.079 & 6.492 & 3265.220 \\
\hline & $-10 \%$ & 0.450 & 274.411 & 7.238 & 1928.139 & 255.137 & 6.302 & 3509.587 & 257.873 & 6.413 & 3257.564 \\
\hline & $-20 \%$ & 0.400 & 274.309 & 7.201 & 1925.044 & 255.037 & 6.270 & 3505.001 & 257.773 & 6.380 & 3253.193 \\
\hline \multirow{4}{*}{$\chi(500)$} & $20 \%$ & 600.000 & 600.000 & 7.328 & 1927.490 & 255.259 & 6.381 & 3509.871 & 257.997 & 6.493 & 3257.708 \\
\hline & $10 \%$ & 550.000 & 550.000 & 7.304 & 1929.198 & 255.249 & 6.360 & 3511.833 & 257.986 & 6.472 & 3259.636 \\
\hline & $-10 \%$ & 450.000 & 450.000 & 7.255 & 1932.633 & 255.228 & 6.318 & 3515.777 & 257.965 & 6.429 & 3263.512 \\
\hline & $-20 \%$ & 400.000 & 400.000 & 7.230 & 1934.359 & 255.217 & 6.297 & 3517.759 & 257.954 & 6.408 & 3265.459 \\
\hline \multirow{4}{*}{$\zeta(1000)$} & $20 \%$ & 1200.000 & 274.705 & 7.661 & 1904.138 & 255.402 & 6.667 & 3483.047 & 258.143 & 6.785 & 3231.349 \\
\hline & $10 \%$ & 1100.000 & 274.611 & 7.472 & 1917.355 & 255.321 & 6.505 & 3498.230 & 258.060 & 6.620 & 3246.269 \\
\hline & $-10 \%$ & & & 7.082 & & 255.153 & 6.169 & 3529.792 & 257.889 & 6.277 & 3277.285 \\
\hline & $-20 \%$ & 800.000 & 274.314 & 6.879 & 1959.165 & 255.066 & 5.994 & 3546.236 & 257.799 & 6.099 & 3293.445 \\
\hline \multirow{4}{*}{$\hbar(2)$} & $20 \%$ & 2.400 & 274.874 & 6.665 & 1880 & 255.547 & 5.798 & 345 & 258.290 & 5.9 & 3204.722 \\
\hline & $10 \%$ & 2.200 & 274.698 & 6.951 & 1905.144 & 255.396 & 6.050 & 3484.203 & 258.136 & 6.157 & 3232.485 \\
\hline & $-10 \%$ & 1.800 & 274.322 & 7.661 & 1958.047 & 255.072 & 6.675 & 3544.953 & 257.806 & 6.792 & 3292.184 \\
\hline & $-20 \%$ & 1.600 & 274.120 & 8.112 & 1986.783 & 254.898 & 7.072 & 3577.924 & 257.628 & 7.196 & 3324.587 \\
\hline \multirow{4}{*}{$\omega(150)$} & $20 \%$ & 180.000 & 293.494 & 8.787 & 814.828 & 270.045 & 7.024 & 2257.755 & 273.355 & 7.211 & 2013.351 \\
\hline & $10 \%$ & 165.000 & 283.949 & 7.923 & 1321.012 & 262.628 & 6.655 & 2853.657 & 265.649 & 6.798 & 2602.859 \\
\hline & $-10 \%$ & 135.000 & 265.149 & 6.774 & 2643.576 & 247.869 & 6.065 & 4237.982 & 250.326 & 6.152 & 3989.230 \\
\hline & $-20 \%$ & 120.000 & 255.831 & 6.363 & 3458.375 & 240.517 & 5.824 & 5026.037 & 242.696 & 5.893 & 4785.642 \\
\hline \multirow{4}{*}{$F_{C}(200)$} & $20 \%$ & 240.000 & 274.630 & 7.510 & 1914.685 & 255.338 & 6.538 & 3495.164 & 258.077 & 6.653 & 3243.255 \\
\hline & $10 \%$ & 220.000 & 274.573 & 7.396 & 1922.735 & 255.288 & 6.439 & 3504.411 & 258.026 & 6.553 & 3252.342 \\
\hline & $-10 \%$ & 180.000 & 274.456 & 7.161 & 1939.223 & 255.187 & 6.237 & 3523.344 & 257.924 & 6.347 & 3270.948 \\
\hline & $-20 \%$ & 160.000 & 274.396 & 7.042 & 1947.672 & 255.136 & 6.134 & 3533.044 & 257.871 & 6.242 & 3280.480 \\
\hline \multirow{4}{*}{$N_{t}(6)$} & $20 \%$ & .000 & 276.047 & 10. & & & 8.967 & & 2 & 9.1 & 3022.364 \\
\hline & $10 \%$ & 8.000 & 275.654 & 9.558 & 1772.825 & 256.217 & 8.296 & 3331.964 & 258.972 & 8.445 & 3082.910 \\
\hline & $-10 \%$ & 4.000 & 274.766 & 7.783 & 1895.591 & 255.455 & 6.772 & 3473.225 & 258.196 & 6.892 & 3221.698 \\
\hline & $-20 \%$ & 2.000 & 274.246 & 6.742 & 1968.856 & 255.007 & 5.876 & 3557.357 & 257.739 & 5.979 & 3304.374 \\
\hline & $20 \%$ & 120.000 & 277.083 & 7.515 & 1751.504 & 257.773 & 6.508 & 6.862 & 260.513 & 6.627 & 3032.791 \\
\hline & $10 \%$ & 110.000 & 275.798 & 7.396 & 1840.244 & 256.505 & 6.423 & 3394.380 & 259.244 & 6.538 & 3146.228 \\
\hline$\ell(100)$ & $-10 \%$ & 90.000 & 273.233 & 7.166 & 2023.510 & 253.972 & 6.257 & 3635.126 & 256.708 & 6.365 & 3378.819 \\
\hline & $-20 \%$ & 80.000 & 271.953 & 7.056 & 2118.033 & 252.707 & 6.176 & 3758.353 & 255.441 & 6.281 & 3497.972 \\
\hline & $20 \%$ & 1.200 & 274.550 & 7.349 & 1925.991 & 255.268 & 6.399 & 3508.150 & 258.006 & 6.512 & 3256.016 \\
\hline & $10 \%$ & 1.100 & 274.532 & 7.314 & 1928.446 & 255.253 & 6.369 & 3510.969 & 257.991 & 6.481 & 3258.787 \\
\hline & $-10 \%$ & 0.900 & 274.497 & 7.244 & 1933.392 & 255.223 & 6.309 & 3516.648 & 257.960 & 6.420 & 3264.368 \\
\hline & $-20 \%$ & 0.800 & 274.479 & 7.209 & 1935.882 & 255.208 & 6.278 & 3519.508 & 257.944 & 6.389 & 3267.179 \\
\hline & $20 \%$ & 0.360 & 276.872 & 7.495 & 1765.910 & 257.565 & 6.493 & 3295.975 & 260.306 & 6.611 & 3051.237 \\
\hline & $10 \%$ & 0.330 & 275.693 & 7.386 & 1847.598 & 256.401 & 6.415 & 3404.086 & 259.140 & 6.530 & 3155.600 \\
\hline$\alpha(0.30)$ & $-10 \%$ & 0.270 & 273.338 & 7.176 & 2015.853 & 254.076 & 6.264 & 3625.122 & 256.811 & 6.372 & 3369.148 \\
\hline & $-20 \%$ & 0.240 & 272.162 & 7.075 & 2102.417 & 252.914 & 6.190 & 3738.045 & 255.648 & 6.296 & 3478.330 \\
\hline
\end{tabular}


Table 2. Cont.

\begin{tabular}{|c|c|c|c|c|c|c|c|c|c|c|c|}
\hline \multirow{2}{*}{$\begin{array}{l}\text { Parameter } \\
\text { (Base) }\end{array}$} & \multirow{2}{*}{$\begin{array}{c}\text { Change } \\
\text { in } \%\end{array}$} & \multirow{2}{*}{$\begin{array}{l}\text { Changed } \\
\text { Value }\end{array}$} & \multicolumn{3}{|c|}{ Case I } & \multicolumn{3}{|c|}{ Case II } & \multicolumn{3}{|c|}{ Case III } \\
\hline & & & $p$ & $T_{c}$ & $\operatorname{Profit}\left(\tau_{N}\right)$ & $p$ & $T_{c}$ & Profit $\left(\tau_{f}\right)$ & $p$ & $T_{c}$ & Profit $(\tau)$ \\
\hline \multirow{4}{*}{$c_{p}(1.50)$} & $20 \%$ & 1.800 & 276.837 & 7.423 & 1770.736 & 257.535 & 6.432 & 3301.545 & 260.275 & 6.549 & 3056.708 \\
\hline & $10 \%$ & 1.650 & 275.675 & 7.350 & 1850.041 & 256.386 & 6.385 & 3406.898 & 259.125 & 6.499 & 3158.363 \\
\hline & $-10 \%$ & 1.350 & 273.355 & 7.211 & 2013.351 & 254.091 & 6.294 & 3622.255 & 256.827 & 6.403 & 3366.330 \\
\hline & $-20 \%$ & 1.200 & 272.197 & 7.144 & 2097.353 & 252.944 & 6.250 & 3732.257 & 255.678 & 6.356 & 3472.639 \\
\hline \multirow{4}{*}{$\begin{array}{c}w_{p} \\
(0.50)\end{array}$} & $20 \%$ & 0.600 & 276.837 & 7.423 & 1770.736 & 257.535 & 6.432 & 3301.545 & 260.275 & 6.549 & 3056.708 \\
\hline & $10 \%$ & 0.550 & 275.675 & 7.350 & 1850.041 & 256.386 & 6.385 & 3406.898 & 259.125 & 6.499 & 3158.363 \\
\hline & $-10 \%$ & 0.450 & 273.355 & 7.211 & 2013.351 & 254.091 & 6.294 & 3622.255 & 256.827 & 6.403 & 3366.330 \\
\hline & $-20 \%$ & 0.400 & 272.197 & 7.144 & 2097.353 & 252.944 & 6.250 & 3732.257 & 255.678 & 6.356 & 3472.639 \\
\hline \multirow{4}{*}{$c_{e}(0.03)$} & $20 \%$ & 0.036 & 274.518 & 7.286 & 1930.418 & 255.241 & 6.345 & 3513.234 & 257.978 & 6.457 & 3261.013 \\
\hline & $10 \%$ & 0.033 & 274.516 & 7.283 & 1930.666 & 255.240 & 6.342 & 3513.518 & 257.977 & 6.454 & 3261.292 \\
\hline & $-10 \%$ & 0.027 & 274.513 & 7.276 & 1931.160 & 255.237 & 6.336 & 3514.086 & 257.974 & 6.447 & 3261.850 \\
\hline & $-20 \%$ & 0.024 & 274.511 & 7.272 & 1931.408 & 255.235 & 6.333 & 3514.370 & 257.972 & 6.444 & 3262.129 \\
\hline \multirow{4}{*}{$c_{k}(0.02)$} & $20 \%$ & 0.024 & 274.721 & 7.292 & 1916.421 & 255.442 & 6.347 & 3494.684 & 258.180 & 6.459 & 3243.109 \\
\hline & $10 \%$ & 0.022 & 274.618 & 7.286 & 1923.661 & 255.340 & 6.343 & 3504.237 & 258.077 & 6.455 & 3252.334 \\
\hline & $-10 \%$ & 0.018 & 274.412 & 7.273 & 1938.177 & 255.136 & 6.335 & 3523.379 & 257.873 & 6.446 & 3270.820 \\
\hline & $-20 \%$ & 0.016 & 274.308 & 7.267 & 1945.454 & 255.034 & 6.331 & 3532.969 & 257.771 & 6.442 & 3280.081 \\
\hline
\end{tabular}

\subsection{Managerial Implications}

The managerial implications of this sustainable inventory management study in terms of pricing strategies, low carbon preferences, suitability of discount policy, and impact of payments in advance are vast:

(i) From the three observed cases, the lowest selling price is obtained when the payment in advance is performed in a single payment. Further study also confirms that profit is higher for a smaller number of instalments; hence, managers can optimize the number of installments in this direction considering their financial condition.

(ii) The case with a single payment also results in a lower selling price. It is beneficial for customers and increases the demand level.

(iii) One can take important pricing decisions from the study and maintain a healthy profit margin by incorporating these strategies and simultaneously observing the nature of the customers.

(iv) This study provides some insights into how preferences for low carbon can influence the sales of the retailer and in which way a manager can maintain an eco-friendly inventory. This study shows that the total profit increases with higher values of carbon emission reduction level and higher preferences for low carbon among customers.

\section{Conclusions}

This paper presents a low-carbon preference inventory model with selling price and carbon-emission-reduction-dependent demand. Some major issues solved through this model are:

(i) The optimal replenishment rate clinging to the commencement of payment in advance has been successfully integrated and offers some significant results.

(ii) Simultaneous integration of discount policy, payment in advance to the selling price, and reduction of carbon-emission-dependent demand work efficiently. It provides some techniques for the retailer to manage inventories profitably.

(iii) A smaller number of instalments of the payment in advance increase the profit. This study shows that the case with a single payment results in a higher total profit and a lower selling price.

(iv) With the increasing customers' preferences for environmentally friendly products, retailers should increase the effort for reducing emission levels. 
Therefore, to maximize profit, this study recommends that retailers respond to the increasing customers' preferences for low carbon by promoting environmentally friendly products. Simultaneously, retailers should attract more customers by setting a lower price by minimizing the number of instalments to take advantage of the discounts offered.

However, this model has limitations in terms of exposition, choice of variables, incorporation of marketing strategies, etc. This model can easily be extended by incorporating trade-credit policy $[40,44,45]$, including some carbon emission regulations $[33,46]$ and taking more than one player, e.g., a vendor-buyer system $[47,48]$. This study also does not allow for shortages; hence, further research may consider shortages with a full or partial backlog. Moreover, the retailer can dynamically purchase the inventory from the outside supplier to reduce the financial risk and avail the full discount facilities.

Author Contributions: Conceptualization, S.S. and A.H.M.M.; methodology, S.S. and A.H.M.M.; software, S.S. and S.M.; validation, S.S., A.H.M.M., A.A., and I.M.H.; writing-original draft preparation, S.S., A.H.M.M., S.M., and Y.D.; writing—review and editing, S.S., A.H.M.M., Y.D., A.A., and I.M.H.; visualization, S.S., S.M., I.M.H. and A.H.M.M. All authors have read and agreed to the published version of the manuscript.

Funding: This work was supported by the Research Supporting Project No. (RSP-2021/389), King Saud University, Riyadh, Saudi Arabia.

Institutional Review Board Statement: Not applicable.

Informed Consent Statement: Not applicable.

Data Availability Statement: All data are given in the manuscript which is used to justify the proposed model.

Acknowledgments: We would like to thank the editors of the journal as well as the anonymous reviewers for their valuable suggestions that make the paper stronger and more consistent.

Conflicts of Interest: The authors declare no conflict of interest.

\section{References}

1. Borin, N.; Lindsey-Mullikin, J.; Krishnan, R. An analysis of consumer reactions to green strategies. J. Prod. Brand Manag. 2013, 22, 118-128. [CrossRef]

2. Lin, R.-J.; Tan, K.-H.; Geng, Y. Market demand, green product innovation, and firm performance: Evidence from Vietnam motorcycle industry. J. Clean. Prod. 2013, 40, 101-107. [CrossRef]

3. Zhang, Q.; Zhao, Q.; Zhao, X.; Tang, L. On the introduction of green product to a market with environmentally conscious consumers. Comput. Ind. Eng. 2020, 139, 106190. [CrossRef]

4. Fernando, Y.; Wah, W.X. The impact of eco-innovation drivers on environmental performance: Empirical results from the green technology sector in Malaysia. Sustain. Prod. Consum. 2017, 12, 27-43. [CrossRef]

5. Yalabik, B.; Fairchild, R.J. Customer, regulatory, and competitive pressure as drivers of environmental innovation. Int. J. Prod. Econ. 2011, 131, 519-527. [CrossRef]

6. Pang, Q.; Li, M.; Yang, T.; Shen, Y. Supply chain coordination with carbon trading price and consumers' environmental awareness dependent demand. Math. Probl. Eng. 2018, 2018, 8749251. [CrossRef]

7. Xia, L.; Hao, W.; Qin, J.; Ji, F.; Yue, X. Carbon emission reduction and promotion policies considering social preferences and consumers' low-carbon awareness in the cap-and-trade system. J. Clean. Prod. 2018, 195, 1105-1124. [CrossRef]

8. Xia, L.; Guo, T.; Qin, J.; Yue, X.; Zhu, N. Carbon emission reduction and pricing policies of a supply chain considering reciprocal preferences in cap-and-trade system. Ann. Oper. Res. 2017, 268, 149-175. [CrossRef]

9. Zanoni, S.; Mazzoldi, L.; Zavanella, L.E.; Jaber, M.Y. A joint economic lot size model with price and environmentally sensitive demand. Prod. Manuf. Res. 2014, 2, 341-354. [CrossRef]

10. Sana, S.S. A structural mathematical model on two echelon supply chain system. Ann. Oper. Res. 2021. [CrossRef]

11. Hovelaque, V.; Bironneau, L. The carbon-constrained EOQ model with carbon emission dependent demand. Int. J. Prod. Econ. 2015, 164, 285-291. [CrossRef]

12. Tsai, P.-H.; Lin, G.-Y.; Zheng, Y.-L.; Chen, Y.-C.; Chen, P.-Z.; Su, Z.-C. Exploring the effect of Starbucks' green marketing on consumers' purchase decisions from consumers' perspective. J. Retail. Consum. Serv. 2020, 56, 102162. [CrossRef]

13. Nekmahmud, M.; Fekete-Farkas, M. Why not green marketing? Determinates of consumers' intention to green purchase decision in a new developing nation. Sustainability 2020, 12, 7880. [CrossRef]

14. Grant, J. Green marketing. Strateg. Dir. 2008, 24, 25-27. [CrossRef]

15. Ginsberg, J.; Bloom, P. Choosing the right green marketing strategy. MIT Sloan Manag. Rev. 2004, 79-84. 
16. Lampe, M.; Gazda, G.M. Green marketing in Europe and the United States: An evolving business and society interface. Int. Bus. Rev. 1995, 4, 295-312. [CrossRef]

17. Dong, G.; Liang, L.; Wei, L.; Xie, J.; Yang, G. Optimization model of trade credit and asset-based securitization financing in carbon emission reduction supply chain. Ann. Oper. Res. 2021, 299, 1-50. [CrossRef]

18. Zhang, Q.; Tsao, Y.-C.; Chen, T.-H. Economic order quantity under advance payment. Appl. Math. Model. 2014, 38, 5910-5921. [CrossRef]

19. Taleizadeh, A.A.; Tavakoli, S.; San-José, L.A. A lot sizing model with advance payment and planned backordering. Ann. Oper. Res. 2018, 271, 1001-1022. [CrossRef]

20. Li, R.; Skouri, K.; Teng, J.-T.; Yang, W.-G. Seller's optimal replenishment policy and payment term among advance, cash, and credit payments. Int. J. Prod. Econ. 2018, 197, 35-42. [CrossRef]

21. Maiti, A.K.; Maiti, M.K.; Maiti, M. Inventory model with stochastic lead-time and price dependent demand incorporating advance payment. Appl. Math. Model. 2009, 33, 2433-2443. [CrossRef]

22. Taleizadeh, A.A. An economic order quantity model for deteriorating item in a purchasing system with multiple prepayments. Appl. Math. Model. 2014, 38, 5357-5366. [CrossRef]

23. Mashud, A.H.M.; Roy, D.; Daryanto, Y.; Chakrabortty, R.K.; Tseng, M.-L. A sustainable inventory model with controllable carbon emissions, deterioration and advance payments. J. Clean. Prod. 2021, 296, 126608. [CrossRef]

24. Sepehri, A. Inventory management under carbon emission policies: A systematic literature review. Decis. Mak. Invent. Manag. 2021, 187-218. [CrossRef]

25. Pattnaik, S.; Nayak, M.M.; Abbate, S.; Centobelli, P. Recent trends in sustainable inventory models: A literature review. Sustainability 2021, 13, 11756. [CrossRef]

26. Lin, T.-Y.; Sarker, B.R. A pull system inventory model with carbon tax policies and imperfect quality items. Appl. Math. Model. 2017, 50, 450-462. [CrossRef]

27. Kazemi, N.; Abdul-Rashid, S.H.; Ghazilla, R.A.R.; Shekarian, E.; Zanoni, S. Economic order quantity models for items with imperfect quality and emission considerations. Int. J. Syst. Sci. Oper. Logist. 2016, 5, 99-115. [CrossRef]

28. Shen, Y.J.; Shen, K.F.; Yang, C.T. A production inventory model for deteriorating items with collaborative preservation technology investment under carbon tax. Sustainability 2019, 11, 5027. [CrossRef]

29. Wee, H.-M.; Daryanto, Y. Imperfect quality item inventory models considering carbon emissions. Optim. Invent. Manag. Asset 2020, 137-159. [CrossRef]

30. Daryanto, Y.; Wee, H.M.; Wu, K.H. Revisiting sustainable EOQ model considering carbon emission. Int. J. Manuf. Technol. Manag. 2021, 35. [CrossRef]

31. Paul, A.; Pervin, M.; Roy, S.K.; Maculan, N.; Weber, G.-W. A green inventory model with the effect of carbon taxation. Ann. Oper. Res. 2021. [CrossRef]

32. As'ad, R.; Hariga, M.; Shamayleh, A. Sustainable dynamic lot sizing models for cold products under carbon cap policy. Comput. Ind. Eng. 2020, 149, 106800. [CrossRef] [PubMed]

33. Hasan, M.R.; Roy, T.C.; Daryanto, Y.; Wee, H.-M. Optimizing inventory level and technology investment under a carbon tax, cap-and-trade and strict carbon limit regulations. Sustain. Prod. Consum. 2021, 25, 604-621. [CrossRef]

34. Datta, T.K. Effect of green technology investment on a production-inventory system with carbon tax. Adv. Oper. Res. 2017, 2017, 4834839. [CrossRef]

35. Mashud, A.H.M.; Pervin, M.; Mishra, U.; Daryanto, Y.; Tseng, M.L.; Lim, M.K. A sustainable inventory model with controllable carbon emissions in green-warehouse farms. J. Clean. Prod. 2021, 298, 126777. [CrossRef]

36. Mishra, U.; Wu, J.-Z.; Tsao, Y.-C.; Tseng, M.-L. Sustainable inventory system with controllable non-instantaneous deterioration and environmental emission rates. J. Clean. Prod. 2020, 244, 118807. [CrossRef]

37. Lou, G.; Xia, H.; Zhang, J.; Fan, T. Investment strategy of emission-reduction technology in a supply chain. Sustainability 2015, 7, 10684-10708. [CrossRef]

38. Gao, X.; Zheng, H.; Zhang, Y.; Golsanami, N. Tax policy, environmental concern and level of emission reduction. Sustainability 2019, 11, 1047. [CrossRef]

39. Teng, J.-T.; Cárdenas-Barrón, L.E.; Chang, H.-J.; Wu, J.; Hu, Y. Inventory lot-size policies for deteriorating items with expiration dates and advance payments. Appl. Math. Model. 2016, 40, 8605-8616. [CrossRef]

40. Mashud, A.H.M.; Wee, H.-M.; Sarkar, B.; Chiang Li, Y.-H. A sustainable inventory system with the advanced payment policy and trade-credit strategy for a two-warehouse inventory system. Kybernetes 2020, 50, 1321-1348. [CrossRef]

41. Savaskan, R.C.; Van Wassenhove, L.N. Reverse channel design: The case of competing retailers. Manag. Sci. 2006, 52, 1-14. [CrossRef]

42. Swami, S.; Shah, J. Channel coordination in green supply chain management. J. Oper. Res. Soc. 2013, 64, 336-351. [CrossRef]

43. Taleizadeh, A.A. Lot-sizing model with advance payment pricing and disruption in supply under planned partial backordering. Int. Trans. Oper. Res. 2016, 24, 783-800. [CrossRef]

44. Wang, J.; Wang, K.; Li, X.; Zhao, R. Suppliers' trade credit strategies with transparent credit ratings: Null, exclusive, and nonchalant provision. Eur. J. Oper. Res. 2022, 297, 153-163. [CrossRef]

45. Tiwari, S.; Cárdenas-Barrón, L.E.; Malik, A.I.; Jaggi, C.K. Retailer's credit and inventory decisions for imperfect quality and deteriorating items under two-level trade credit. Comput. Oper. Res. 2022, 138, 105617. [CrossRef] 
46. Rout, C.; Paul, A.; Kumar, R.S.; Chakraborty, D.; Goswami, A. Integrated optimization of inventory, replenishment and vehicle routing for a sustainable supply chain under carbon emission regulations. J. Clean. Prod. 2021, 316, 128256. [CrossRef]

47. Marchi, B.; Zanoni, S.; Jaber, M.Y. Credit-dependent demand in a vendor-buyer model with a two-level delay-in-payments contract under a consignment-stock policy agreement. Appl. Math. Model. 2021, 99, 585-605. [CrossRef]

48. Wangsa, I.D.; Tiwari, S.; Wee, H.M.; Reong, S. A sustainable vendor-buyer inventory system considering transportation, loading and unloading activities. J. Clean. Prod. 2020, 271, 122120. [CrossRef] 